\title{
Executive Function in Pediatric Bipolar Disorder and Attention-Deficit Hyperactivity Disorder: In Search of Distinct Phenotypic Profiles
}

\author{
Patricia D. Walshaw $\cdot$ Lauren B. Alloy $\cdot$ Fred W. Sabb
}

Received: 4 September 2009 / Accepted: 21 December 2009/Published online: 18 February 2010

(C) The Author(s) 2010. This article is published with open access at Springerlink.com

\begin{abstract}
Often, there is diagnostic confusion between bipolar disorder (BD) and attention-deficit hyperactivity disorder (ADHD) in youth due to similar behavioral presentations. Both disorders have been implicated as having abnormal functioning in the prefrontal cortex; however, there may be subtle differences in the manner in which the prefrontal cortex functions in each disorder that could assist in their differentiation. Executive function is a construct thought to be a behavioral analogy to prefrontal cortex functioning. We provide a qualitative review of the literature on performance on executive function tasks for $\mathrm{BD}$ and ADHD in order to determine differences in task performance and neurocognitive profile. Our review found primary differences in executive function in the areas of interference control, working memory, planning, cognitive flexibility, and fluency. These differences may begin to establish a pediatric $\mathrm{BD}$ profile that provides a more objective means of differential diagnosis between $\mathrm{BD}$ and ADHD when they are not reliably distinguished by clinical diagnostic methods.
\end{abstract}

Keywords Bipolar disorder - Attention-deficit hyperactivity disorder - Executive function - Prefrontal cortex .

Neurocognitive

P. D. Walshaw $(\bowtie) \cdot$ F. W. Sabb

Department of Psychiatry and Biobehavioral Science,

University of California Los Angeles,

Los Angeles, CA, USA

e-mail: pwalshaw@mednet.ucla.edu

L. B. Alloy

Department of Psychology, Temple University,

Philadelphia, PA, USA

\section{Introduction}

In 2001, the National Institute of Mental Health (NIMH) Roundtable on Prepubertal Bipolar Disorder proposed the diagnosis of BD in children (NIMH Roundtable 2001). The diagnosis, however, still remains somewhat controversial and often misused because of a lack of research in the heterogeneity of the disorder in youth (e.g., Geller et al. 2000, 2002; Wozniak et al. 1995). The clinical presentation of BD in adults often has an episodic course, with individuals switching from distinct affective episodes of depression, mania or hypomania, and euthymia. In children, however, agreement on the clinical presentation of BD is less clear, with some studies indicating a more chronic course of symptoms with ultra-rapid shifting of mood states from euphoria to irritability (Geller et al. 2004) or a more irritable and violent presentation during manic states (Wozniak et al. 1995). Perhaps unsurprisingly, more recent studies have indicated that narrowly defining the presentation to adult DSM-IV criteria yields different results in cognitive deficits and brain activation patterns than when the criteria are more loosely defined (Leibenluft et al. 2007; Rich et al. 2007). Despite the heterogeneity of the clinical presentation in children, BD is still considered a valid diagnosis in pediatric populations (see Youngstrom et al. 2008, for a review).

An added complication in the diagnosis of bipolar disorder in pediatric populations is the considerable overlap of symptoms with Attention-Deficit Hyperactivity Disorder (ADHD). Hypomania and mania in BD share with ADHD the symptoms of excessive talking, increased activity, inappropriate actions and verbal responses in social situations, lack of inhibition, and distractibility (Geller et al. 2002; see Kent and Craddock 2003). Additionally, the hallmark feature of chronic irritability in childhood mania 
can often mimic the chronic low frustration tolerance and emotional lability of ADHD (Geller et al. 2002; Wozniak et al. 1995). It is estimated that the comorbidity between BD and ADHD in youth ranges from 60-93\% (Axelson et al. 2006; Faraone et al. 1997; Geller et al. 2000, 2004; Wozniak et al. 1995). Although it has been described as a distinct diagnostic category (Geller et al. 2002, 2004; Youngstrom et al. 2008), only a limited number of studies have examined BD in youth without this comorbidity or compared the two disorders directly (see Kent and Craddock 2003; Rucklidge 2006). If pediatric BD is to be considered a distinct diagnostic entity, further work must examine its presentation in the absence of comorbidity with ADHD. Given the limited understanding of BD in youth, the differential diagnosis between BD and ADHD remains a controversial issue.

The primary aim of this review is to directly examine the quantitative similarities and differences in executive functioning between $\mathrm{BD}$ and $\mathrm{ADHD}$ in order to determine if a distinct neurocognitive profile exists for each. Both disorders are currently diagnosed using a clinical interview and self-report checklists completed by the individual, a parent, or teacher. Unfortunately, the diagnostician must rely on self-report evidence and clinical judgment to arrive at a diagnosis, as there is no valid biological or behavioral test for arriving at the diagnosis. It is tenuous, however, to rely solely on self-reported characteristics to form a differential diagnosis for these disorders given the behaviorally similar presentation in childhood. Much of the controversy regarding the diagnosis of pediatric BD lies in the Bipolar Disorder Not Otherwise Specified (BDNOS) category. As this is a more broad-reaching category including symptoms of BD that do not reach the threshold for full diagnostic criteria, there is often confusion on whether BD or a disruptive behavior disorder, such as ADHD, should be diagnosed when children present as chronically irritable and emotionally labile (Galantar and Leibenluft 2008). While several researchers have made attempts to define the BD phenotype as more narrowly conforming to the adult criteria for $\mathrm{BD}$ (Leibenluft and Rich 2008; Stringaris et al. 2009), there remains no clear-cut answer for the definition of BDNOS in pediatric samples.

The inherent problems in differential diagnosis from BD warrant the use of more objective supporting evidence, such as neuroimaging and cognitive testing, to assist in diagnosis in children and adolescents, although some have questioned this approach in ADHD (Barkley and Grodzinsky 1994). This objective data, however, would provide supporting evidence for differing neural networks that occur in pediatric $\mathrm{BD}$ and ADHD, despite similar behavioral presentations. Research in magnetic resonance imaging (MRI) and diffusion tensor imaging (DTI), indicate differences in structural abnormalities in BD versus ADHD, with volumetric abnormalities of the limbic system and smaller volume of the ventrolateral prefrontal cortex (VLPFC) and rostral prefrontal cortex (PFC) implicated in pediatric BD and smaller volume of striatal structures implicated in ADHD but not BD (Blumberg et al. 2005; Kalmar et al. 2009; Lopez-Larson et al. 2009). Disruption in white matter appears more diffuse across the brain regions in ADHD as compared to $\mathrm{BD}$, whereas white matter abnormalities are more restricted to cortico-limbic connections in the PFC for BD (Pavuluri et al. 2009b). Evidence from functional imaging studies reveal relatively greater activation in the bilateral VLPFC and right dorsolateral PFC (DLPFC) for pediatric $\mathrm{BD}$ relative to the ADHD during response inhibition tasks (Passarotti et al. 2009). Other tasks of executive function indicate greater activation in left DLPFC, bilateral ACC, and left putamen and thalamus for children with BD (Blumberg et al. 2003; Chang et al. 2004; Nelson et al. 2007), whereas children with ADHD exhibit lower activation in right DLPFC and ACC, and striatal areas (Casey et al. 1997; Konrad et al. 2007; Smith et al. 2008). Although there is evidence that individuals with ADHD and BD differ on neuroanatomical structure and function, such neurobiological measurements (e.g., MRI, SPECT) remain impractical and inefficient in the typical clinical setting. Thus, developing a neurocognitive profile for each disorder would aide in differential diagnosis and avoid the pitfalls of misdiagnosis in youth.

\section{Executive Function as a Model}

The PFC and its related neural circuitry are critically involved in executing many of the components underlying executive function. Pennington's (1997) concept of the "frontal metaphor" applies to the term "executive function", in that executive function is a latent construct born from theory and, thus, is not an exact representation of the activity in PFC. Measurement of executive function thus proves difficult, as it is a latent construct composed of several components, which are not clearly defined. Factor analyses of test batteries of executive function do not result in a single factor, but at least five factors: 1) inhibition, 2) working memory, 3) planning, 4) set-shifting, and 5) fluency. (Pennington 1997; Pennington et al. 1996; Welsh et al. 1991) A recent review of a highly similar latent construct, cognitive control, suggests similar dimensions based on literature mining (Sabb et al. 2008). Although five distinct dimensions, these components of executive function are interrelated processes that depend on interactions with the others to execute control over behavior. Thus, here we use the term 'executive function' to refer to the overarching representation of PFC function, recognizing that this latent construct is multifactorial and remains ill-defined. 
Executive Function, BD, and ADHD

The present review examines BD and ADHD as disorders of the PFC, although it is clear that many areas of the brain are implicated. Although both BD and ADHD show both abnormal PFC functioning and deficits in executive function, there may be distinct signatures in the patterns of deficits that suggest two different disorders. Pennington (1997) notes that, in general, while two separate disorders may both involve dysfunction of the PFC and have similar behavioral presentations, discriminant validity may arise from deficits in different areas of executive function. For example, individuals with schizophrenia have been shown to have greater impairment in some aspects of problem-solving than individuals with $\mathrm{BD}$, but not in the areas of set-shifting and attention (see Bearden et al. 2001, for review).

Here we review five facets of executive function through neurocognitive tasks found in both the pediatric BD and ADHD literatures (see Table 1 for a summary of domains of executive functioning and tasks examined in this review). To the best of our knowledge, this is the first review comparing the neurocognitive function of individuals with pediatric BD and ADHD, and while several studies have emerged to provide support for a neurocognitive profile of pediatric BD research in this new field remains scant. We end our review with a discussion of the executive functioning differences in BD and ADHD and their implications for differential diagnosis of these two disorders.

\section{Method}

The current review was conducted following an extensive search through the research databases PsychInfo and Medline. Key terms were selected based on previous factor analyses on executive function and review papers in the areas of BD and ADHD. Terms included, 'bipolar', 'mania', 'manic', 'euthymic', 'ADHD', 'attention-deficit disorder', and 'hyperactivity', and were cross-referenced with the terms 'cognitive', 'neuropsychological', 'executive', 'prefrontal', 'inhibition', 'working memory', 'planning', 'fluency', and 'set-shifting'. Articles were selected based on the following criteria: use of English language, conducted between the years of 1989 and 2009, clear presentation of results for variables of interest, and use of children or adolescents. Additionally, bibliographies of the articles selected were used to supplement citations that had not been acquired through the database literature search. For the purposes of consistency in measurement, we only review tasks that have been validated in the literature and have been studied in both pediatric BD and ADHD samples.
Sixty-eight studies in ADHD and sixteen studies in pediatric BD were included in the review. Given the paucity of research conducted on pediatric BD to date with most studies having small sample sizes themselves, we chose to present quantitative data from these studies noting their sample sizes and effect sizes, but not conduct a formal meta-analytic review, which may be biased by small numbers of studies with small sample sizes. A majority of these studies are new, suggesting a burgeoning and important field, which will hopefully allow for more strict meta-analyses to be conducted in the future.

All studies selected utilized diagnostic criteria from either DSM-III-R or DSM-IV in their methodology. Due to the nascence of research in pediatric $\mathrm{BD}$, all but one of the BD studies used DSM-IV criteria. In the ADHD literature, 24 studies used DSM-III-R criteria and 44 studies used DSM-IV criteria. Studies on BD were included if subjects met criteria for bipolar I disorder, bipolar II disorder, and bipolar disorder not otherwise specified (BDNOS). Not all studies examined all executive function variables in this included review; 23 studies were single measure studies and 59 used more than one task or a battery. One study included examined cognitive performance in at-risk adolescents who later developed bipolar disorder (Meyer et al. 2004). Eleven of the 16 BD studies included statistics on comorbid ADHD, the average rate of which was $54 \%$. Effects of comorbidity are noted where appropriate in the review. As in most studies of $\mathrm{BD}$, pediatric samples were taking one or more medications at the time of testing. Where examined, effects of medication were found not to produce differences in performance in four of those five studies (Del Bello et al. 2004; Leibenluft et al. 2007; Pavuluri et al. 2006). The remaining study found that psychotropic medication was associated with a decrease in verbal fluency score (Bearden et al. 2007).

Although approximately a third of studies (21 total) reviewed from the ADHD literature distinguished subtypes of ADHD or included analyses on comorbid learning disabilities (LD; 21 total), the majority did not and these factors were combined in the overall findings. Subtype and comorbid LD findings are noted in this review where appropriate, but because the ADHD literature does not always distinguish them, this is noted as a limitation to the conclusions of the present review. For all ADHD studies reviewed, children and adolescents were either off of medication for $>24$ hours or medication naïve. For both BD and ADHD literature, studies included were sampled from a variety of populations, but included mostly outpatient or community samples $(97 \%)$.

To provide a more comprehensive review in comparing these two groups, we have calculated average effect size (ES), weighted by sample size, for each of the tasks 
for each group (ADHD and BD) using Cohen's $d$ (Cohen 1988).

$$
\mathrm{ES}=\frac{\sum_{i=1}^{n_{i}} d_{i} n_{i}}{\sum_{i=1}^{n_{i}} n_{i}}
$$

In order to reduce bias from a particular sample, only a single contribution from each independent sample was used; thus, if a study examined two tasks from the same domain of executive functioning, only the larger of the two effect sizes was used in the average weighted effect size calculation presented in Table 2. Descriptors for effect size are provided for relative comparison and are as defined by Cohen (1988): small $=0.2$, medium $=0.5$, large $>0.8$. An absolute difference score was calculated between the average weighted effect sizes of the two groups. This was used to create a visual presentation of these findings in Fig. 1, which illustrates the areas of executive function showing the largest difference on the left to the smallest difference on the right. Weighted effect sizes for each study are provided in Table 3 for ADHD and Table 4 for BD. As there are only two studies to date that has directly compared executive function in pure pediatric BD and pure ADHD (Passarotti et al. 2009; Rucklidge 2006), all effect sizes presented are each population as compared to control groups. It should be noted that effect sizes for non-significant findings were included and all findings were indicative of either worse performance or no difference from control group.

\section{Results}

Inhibition

Inhibition is a component of executive function that can be broken into several subsystems (see Barkley 1997; Nigg 2000; Tannock 1998, for reviews; Quay 1988, 1997; Schachar and Logan 1990). Barkley (1997) proposes a comprehensive theory of inhibition that consists of three interrelated processes based on both timing and situation in which stimuli are presented including inhibition in regard to an initial response to a stimulus or an ongoing response (Response Inhibition), and inhibition of interfering stimuli (Interference Control).

\section{Response Inhibition}

Response inhibition is the process of physically inhibiting a response to a stimulus. Several behavioral tasks have been developed to measure response inhibition; two of which have been examined in the pediatric BD and ADHD literatures: go/no-go style variants of the Continuous Performance Test

Table 1 Tasks of executive function across pediatric BD and ADHD literature

\begin{tabular}{|c|c|c|c|}
\hline Executive function domain & Tasks & Description & Key scores \\
\hline \multicolumn{4}{|l|}{ Inhibition } \\
\hline Response inhibition & $\begin{array}{l}\text { Continuous Performance } \\
\text { (CPT) } \\
\text { Stop-Signal Task (SST) }\end{array}$ & $\begin{array}{l}\text { Inhibit response when target stimulus shown; } \\
\text { rapid response when other stimuli are shown } \\
\text { Inhibit prepotent response when tone is heard }\end{array}$ & $\begin{array}{l}\text { Errors of commission on } \mathrm{CPT} \\
\text { (CPT-EC) or Stop-signal } \\
\text { reaction time (SSRT) }\end{array}$ \\
\hline Interference control & Stroop task & $\begin{array}{l}\text { Rapidly naming colors (e.g., "green") of ink } \\
\text { in which color words (e.g., "red") are printed }\end{array}$ & Interference score \\
\hline \multicolumn{4}{|l|}{ Working memory } \\
\hline Verbal working memory & $\begin{array}{l}\text { Digit-Span Total (DS-T) } \\
\text { Digit-Span Backward (DS-B) }\end{array}$ & $\begin{array}{l}\text { Repeat a series of numbers in forward or } \\
\text { reverse order from which they are presented; } \\
\text { Total score includes both forward and } \\
\text { backward presentations }\end{array}$ & $\#$ of series of digits correct \\
\hline \multirow[t]{2}{*}{ Spatial working memory } & CANTAB SWM Task & $\begin{array}{l}\text { Maintain spatial memory of already } \\
\text { selected material }\end{array}$ & Between search errors \\
\hline & Spatial Span (SSp) & $\begin{array}{l}\text { Mentally rearrange spatial information and } \\
\text { output a behavioral response }\end{array}$ & $\begin{array}{l}\text { \# of series of blocks/squares } \\
\text { correct }\end{array}$ \\
\hline Planning & Tower of London (ToL) & $\begin{array}{l}\text { Move } 3+\text { rings/balls to match a particular } \\
\text { arrangement, while adhering to specific } \\
\text { rules of how they can be moved }\end{array}$ & Total score (ToL-T) \\
\hline Set-shifting & Wisconsin Card Sort Task & Sort cards according to shifting rules & $\begin{array}{l}\text { Perseverative errors } \\
\text { (WCST-PE) }\end{array}$ \\
\hline \multicolumn{4}{|l|}{ Fluency } \\
\hline Phonemic fluency & F-A-S Test & $\begin{array}{l}\text { Rapidly name words that begin with } \\
\text { ' } F \text { ' (or 'A' or 'S') }\end{array}$ & \# of words \\
\hline Semantic fluency & Categories & Rapidly name words that belong to a category & \# of words \\
\hline
\end{tabular}


Table 2 Average weighted effect size by task

\begin{tabular}{llcc}
\hline Executive function domain & Variable & BD weighted ES & ADHD weighted ES \\
\hline Inhibition & & .40 & .31 \\
Response inhibition & CPT Errors of Commission (CPT-EC) & .60 & .63 \\
& Stop-Signal Reaction Time (SSRT) & .36 \\
Interference control & Stroop interference (Stroop) & .67 & $.38^{\text {a }}$ \\
Working memory & & $.35^{\text {a }}$ & .80 \\
Verbal working memory & Digit-Span Total (DS-T) & .96 \\
Spatial working memory & Digit-Span Backward (DS-B) & .73 \\
Planning & CANTAB SWM - Between Search Errors (SWM-BSE) & .66 \\
Set-shifting & Spatial Span (SSp) & .63 \\
Fluency & Tower of London - Total (ToL) & .77 \\
Phonemic fluency & WSCT - Perseverative Errors (WCST-PE) & .34 \\
Semantic fluency & F-A-S & .38 & .38 \\
\hline
\end{tabular}

CPT Continuous Performance Test, CANTAB Cambridge Neuropsychological Test Automated Battery

${ }^{a}$ These ES's are the result of only one study and are thus not weighted averages

(CPT; Conners 1985, 1992; Gordon 1983; Rosvold et al. 1956), and the Stop-Signal Task (SST; Logan et al. 1984). These tasks may putatively engage two separate processes activated either by inhibition of an initial response or deactivation of an ongoing response to a stimulus. The primary response inhibition variables (or indicators - as we define the independent variables of interest) for these tasks are errors of commission (EC) and stop-signal reaction time (SSRT), respectively.

CPTs are widely used measures of response inhibition in the ADHD literature. Of the 68 child ADHD studies re- viewed here, 21 examined EC on the CPT. Overall, ADHD samples showed $\mathrm{ES}=.56$ on CPT-EC as compared to controls, indicating a moderate effect for ADHD to exhibit a more impulsive response style on the CPT (see Table 2). In comparison, thirteen studies found no deficits in inhibition in children with ADHD, with effect sizes ranging from .07 to 1.27 for EC. Only two studies examined the effects of ADHD subtype on CPT-EC. Tsal et al. (2005) found that inattentive-type was associated with more EC than combined-type, while Willcutt et al. (2005) found no differences between subtypes in EC.
Fig. 1 Executive function domains for bipolar disorder (BD) and attention-deficit hyperactivity disorder (ADHD) organized from largest to smallest absolute differences in average weighted effect sizes

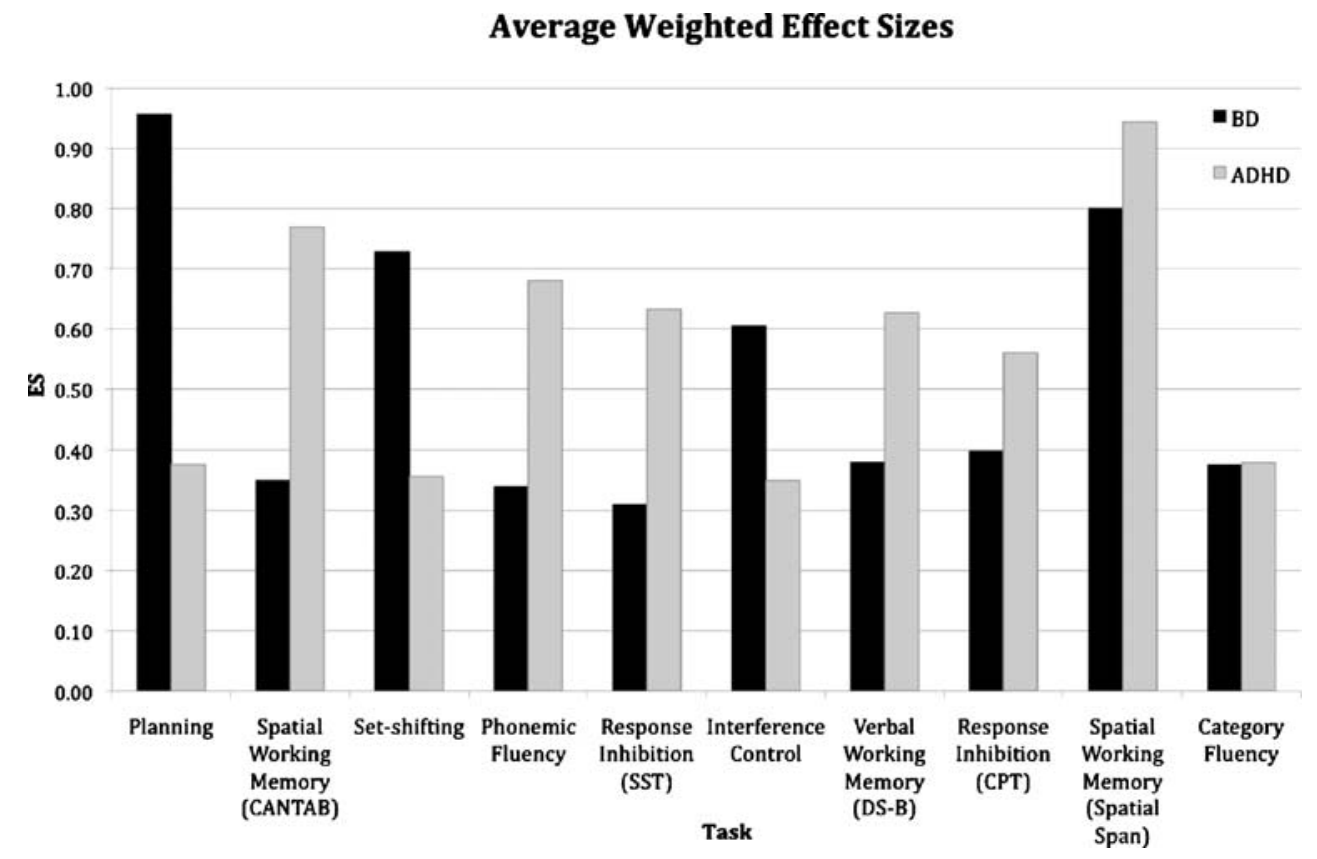


Table 3 ADHD study effect sizes $(d)^{\text {c }}$

\begin{tabular}{|c|c|c|c|c|c|c|c|c|c|c|c|c|}
\hline Reference & $n$ & CPT-EC & SSRT & Stroop & DS-T & DS-B & $\begin{array}{l}\text { SWM- } \\
\text { BSE }\end{array}$ & $\mathrm{SSp}$ & ToL & WCST & FAS & Categories \\
\hline Alloway et al. (2009) & $\begin{array}{l}\mathrm{ADHD}=46 \\
\mathrm{C}=20\end{array}$ & $.14^{\mathrm{b}}$ & - & - & - & - & - & - & - & - & - & - \\
\hline Assesmany et al. (2001) & $\begin{array}{l}\mathrm{ADHD}=40 \\
\mathrm{C}=40\end{array}$ & - & - & - & 1.41 & - & - & - & - & - & - & - \\
\hline Barkley et al. (2001) & $\begin{array}{l}\mathrm{ADHD}=101 \\
\mathrm{C}=39\end{array}$ & $.07^{\mathrm{a}}$ & - & - & - & .22 & - & - & - & - & - & - \\
\hline Barkley et al. (1992) & $\begin{array}{l}\mathrm{ADHD}=24 \\
\mathrm{C}=12\end{array}$ & $1.29^{\mathrm{b}}$ & - & 1.49 & - & - & - & - & - & .46 & .86 & .51 \\
\hline Barnett et al. (2001) & $\begin{array}{l}\mathrm{ADHD}=27 \\
\mathrm{C}=26\end{array}$ & - & - & - & - & - & 1.48 & - & - & - & - & - \\
\hline Bedard et al. (2003) & $\begin{array}{l}\mathrm{ADHD}=59 \\
\mathrm{C}=59\end{array}$ & - & .57 & - & - & - & - & - & - & - & - & - \\
\hline Berlin et al. (2004) & $\begin{array}{l}\mathrm{ADHD}=21 \\
\mathrm{C}=42\end{array}$ & - & - & 1.15 & - & - & - & - & - & - & - & - \\
\hline Borger et al. (1999) & $\begin{array}{l}\mathrm{ADHD}=21 \\
\mathrm{C}=16\end{array}$ & $.65^{\mathrm{b}}$ & - & - & - & - & - & - & - & - & - & - \\
\hline Brewer et al. (2001) & $\begin{array}{l}\mathrm{ADHD}=26 \\
\mathrm{C}=22\end{array}$ & $.38^{\mathrm{b}}$ & - & - & - & - & - & - & - & 1.46 & - & - \\
\hline Cairney et al. (2001) & $\begin{array}{l}\mathrm{ADHD}=13 \\
\mathrm{C}=15\end{array}$ & - & - & - & - & - & 1.13 & - & - & - & - & - \\
\hline Collings (2003) & $\begin{array}{l}\mathrm{ADHD}=46 \\
\mathrm{C}=24\end{array}$ & $.28^{\mathrm{b}}$ & - & - & - & - & - & - & - & - & - & - \\
\hline Corbett et al. (2009) & $\begin{array}{l}\mathrm{ADHD}=18 \\
\mathrm{C}=18\end{array}$ & - & - & .31 & - & - & .21 & .75 & - & - & .03 & .07 \\
\hline Dimoska et al. (2003) & $\begin{array}{l}\mathrm{ADHD}=13 \\
\mathrm{C}=13\end{array}$ & - & 1.37 & - & - & - & - & - & - & - & - & - \\
\hline Epstein et al. (2003) & $\begin{array}{l}\mathrm{ADHD}=21 \\
\mathrm{C}=795\end{array}$ & $.46^{\mathrm{a}}$ & - & - & - & - & - & - & - & - & - & - \\
\hline Geurts et al. (2004) & $\begin{array}{l}\mathrm{ADHD}=54 \\
\mathrm{C}=41\end{array}$ & - & .98 & - & - & - & - & - & .36 & - & .87 & .58 \\
\hline Goldberg et al. (2005) & $\begin{array}{l}\mathrm{ADHD}=12 \\
\mathrm{C}=32\end{array}$ & - & - & .12 & - & - & .57 & - & - & - & - & - \\
\hline Grodzinsky and Diamond (1992) & $\begin{array}{l}\mathrm{ADHD}=66 \\
\mathrm{C}=64\end{array}$ & $.76^{\mathrm{b}}$ & - & 1.11 & - & - & - & - & - & .16 & - & - \\
\hline Happe et al. (2006) & $\begin{array}{l}\mathrm{ADHD}=30 \\
\mathrm{C}=32\end{array}$ & - & - & - & - & - & 1.06 & - & - & - & .63 & .07 \\
\hline Henin et al. (2007) & $\begin{array}{l}\mathrm{ADHD}=102 \\
\mathrm{C}=120\end{array}$ & - & - & .2 & .2 & - & - & - & - & .27 & - & - \\
\hline Horn et al. (1989) & $\begin{array}{l}\mathrm{ADHD}=54 \\
\mathrm{C}=31\end{array}$ & $.83^{\mathrm{b}}$ & - & - & - & - & - & - & - & - & - & - \\
\hline Houghton et al. (1999) & $\begin{array}{l}\mathrm{ADHD}=94 \\
\mathrm{C}=28\end{array}$ & - & - & .17 & - & - & - & - & .15 & .31 & - & - \\
\hline Jennings et al. (1997) & $\begin{array}{l}\mathrm{ADHD}=40 \\
\mathrm{C}=26\end{array}$ & - & .53 & - & - & - & - & - & - & - & - & - \\
\hline Kempton et al. (1999) & $\begin{array}{l}\mathrm{ADHD}=15 \\
\mathrm{C}=15\end{array}$ & - & - & - & - & - & 1.34 & 1.26 & .48 & - & - & - \\
\hline Kerns et al. (2001) & $\begin{array}{l}\mathrm{ADHD}=21 \\
\mathrm{C}=21\end{array}$ & $.23^{\mathrm{a}}$ & - & .45 & - & - & - & - & - & - & - & - \\
\hline Klorman et al. (1999) & $\begin{array}{l}\mathrm{ADHD}=299 \\
\mathrm{C}=28\end{array}$ & - & - & - & - & - & - & - & - & .07 & - & - \\
\hline Konrad et al. (2000) & $\begin{array}{l}\mathrm{ADHD}=16 \\
\mathrm{C}=21\end{array}$ & - & 1.15 & - & - & - & - & - & - & - & - & - \\
\hline Lawrence et al. (2004) & $\begin{array}{l}\mathrm{ADHD}=22 \\
\mathrm{C}=22\end{array}$ & - & - & .12 & - & - & - & - & - & 1.09 & - & - \\
\hline Loge et al. (1990) & $\begin{array}{l}\mathrm{ADHD}=20 \\
\mathrm{C}=20\end{array}$ & $.85^{\mathrm{b}}$ & - & - & - & - & - & - & - & .16 & .17 & .42 \\
\hline Lufi et al. (1990) & $\begin{array}{l}\mathrm{ADHD}=29 \\
\mathrm{C}=20\end{array}$ & - & - & .7 & 1.23 & - & - & - & - & - & - & - \\
\hline
\end{tabular}


Table 3 (continued)

\begin{tabular}{|c|c|c|c|c|c|c|c|c|c|c|c|c|}
\hline Reference & $n$ & CPT-EC & SSRT & Stroop & DS-T & DS-B & $\begin{array}{l}\text { SWM- } \\
\text { BSE }\end{array}$ & $\mathrm{SSp}$ & ToL & WCST & FAS & Categories \\
\hline Manassis et al. (2000) & $\begin{array}{l}\mathrm{ADHD}=30 \\
\mathrm{C}=16\end{array}$ & - & .17 & - & - & - & - & - & - & - & - & - \\
\hline Mariani and Barkley (1997) & $\begin{array}{l}\mathrm{ADHD}=34 \\
\mathrm{C}=30\end{array}$ & $.46^{\mathrm{b}}$ & - & - & - & - & - & - & - & - & - & - \\
\hline Marzoochi et al. (2008) & $\begin{array}{l}\mathrm{ADHD}=35 \\
\mathrm{C}=30\end{array}$ & - & .19 & - & - & - & - & - & 1.0 & - & 1.1 & .13 \\
\hline Mataró et al. (1997) & $\begin{array}{l}\mathrm{ADHD}=11 \\
\mathrm{C}=19\end{array}$ & $.39^{\mathrm{b}}$ & - & .21 & - & - & - & - & - & .35 & 1.02 & .87 \\
\hline McInerney and Kerns (2003) & $\begin{array}{l}\mathrm{ADHD}=30 \\
\mathrm{C}=30\end{array}$ & - & .86 & - & - & .8 & - & - & - & - & - & - \\
\hline McInnes et al. (2003) & $\begin{array}{l}\mathrm{ADHD}=39 \\
\mathrm{C}=19\end{array}$ & - & - & - & - & 1.73 & - & - & - & - & - & - \\
\hline Nigg (1999) & $\begin{array}{l}\mathrm{ADHD}=25 \\
\mathrm{C}=25\end{array}$ & - & .88 & - & - & - & - & - & - & - & - & - \\
\hline Nigg et al. (2002) & $\begin{array}{l}\mathrm{ADHD}=64 \\
\mathrm{C}=41\end{array}$ & - & .8 & - & - & - & - & - & .7 & - & - & - \\
\hline Overtoom et al. (2002) & $\begin{array}{l}\mathrm{ADHD}=16 \\
\mathrm{C}=16\end{array}$ & - & .92 & - & - & - & - & - & - & - & - & - \\
\hline Passarotti et al. (2009) & $\begin{array}{l}\mathrm{ADHD}=15 \\
\mathrm{C}=11\end{array}$ & - & .43 & - & - & - & - & - & - & - & - & - \\
\hline Pennington et al. (1993) & $\begin{array}{l}\mathrm{ADHD}=32 \\
\mathrm{C}=23\end{array}$ & $1.16^{\mathrm{b}}$ & - & - & - & - & - & - & - & .6 & - & - \\
\hline Pineda et al. (1999) & $\begin{array}{l}\mathrm{ADHD}=62 \\
\mathrm{C}=62\end{array}$ & - & - & - & - & - & - & - & - & .65 & .53 & .44 \\
\hline Pliszka (1992) & $\begin{array}{l}\mathrm{ADHD}=92 \\
\mathrm{C}=34\end{array}$ & $.87^{\mathrm{a}}$ & - & - & - & - & - & - & - & - & - & - \\
\hline Pliszka et al. (1997) & $\begin{array}{l}\mathrm{ADHD}=13 \\
\mathrm{C}=14\end{array}$ & - & 1.36 & - & - & - & - & - & - & - & - & - \\
\hline Pliszka et al. (2000) & $\begin{array}{l}\mathrm{ADHD}=10 \\
\mathrm{C}=10\end{array}$ & - & .75 & - & - & - & - & - & - & - & - & - \\
\hline Purvis and Tannock (2000) & $\begin{array}{l}\mathrm{ADHD}=34 \\
\mathrm{C}=17\end{array}$ & $.48^{\mathrm{a}}$ & .61 & - & - & - & - & - & - & - & - & - \\
\hline Rubia et al. (2001) & $\begin{array}{l}\mathrm{ADHD}=16 \\
\mathrm{C}=23\end{array}$ & - & .5 & - & - & - & - & - & - & - & - & - \\
\hline Rucklidge and Tannock (2002) & $\begin{array}{l}\mathrm{ADHD}=59 \\
\mathrm{C}=37\end{array}$ & - & .72 & .31 & - & .65 & - & - & - & - & - & - \\
\hline Rucklidge (2006) & $\begin{array}{l}\mathrm{ADHD}=30 \\
\mathrm{C}=41\end{array}$ & $.32^{\mathrm{a}}$ & - & - & - & - & - & - & - & - & - & - \\
\hline Sartory et al. (2002) & $\begin{array}{l}\mathrm{ADHD}=20 \\
\mathrm{C}=19\end{array}$ & $1.01^{\mathrm{b}}$ & - & - & - & - & - & - & - & .1 & - & - \\
\hline Schachar et al. (2000) & $\begin{array}{l}\mathrm{ADHD}=72 \\
\mathrm{C}=33\end{array}$ & - & .58 & - & - & - & - & - & - & - & - & - \\
\hline Schachar and Tannock (1995) & $\begin{array}{l}\mathrm{ADHD}=40 \\
\mathrm{C}=16\end{array}$ & - & .64 & - & - & - & - & - & - & - & - & - \\
\hline Schachar et al. (1995) & $\begin{array}{l}\mathrm{ADHD}=14 \\
\mathrm{C}=22\end{array}$ & - & .6 & - & - & - & - & - & - & - & - & - \\
\hline Scheres et al. (2001) & $\begin{array}{l}\mathrm{ADHD}=24 \\
\mathrm{C}=41\end{array}$ & - & .39 & - & - & - & - & - & - & - & - & - \\
\hline Schmitz et al. (2002) & $\begin{array}{l}\mathrm{ADHD}=30 \\
\mathrm{C}=60\end{array}$ & - & - & - & - & - & - & - & - & .14 & - & - \\
\hline Seidman et al. (1997a) & $\begin{array}{l}\mathrm{ADHD}=43 \\
\mathrm{C}=36\end{array}$ & - & - & .15 & .73 & - & - & - & - & .21 & - & - \\
\hline Seidman et al. (1997b) & $\begin{array}{l}\mathrm{ADHD}=118 \\
\mathrm{C}=99\end{array}$ & - & - & .31 & - & - & - & - & - & .53 & - & - \\
\hline Shue and Douglas (1992) & $\begin{array}{l}\mathrm{ADHD}=24 \\
\mathrm{C}=24\end{array}$ & - & - & - & - & - & - & - & - & .88 & - & - \\
\hline Solanto et al. (2001) & $\begin{array}{l}\mathrm{ADHD}=77 \\
\mathrm{C}=29\end{array}$ & - & .69 & - & - & - & - & - & - & - & - & - \\
\hline
\end{tabular}


Table 3 (continued)

\begin{tabular}{|c|c|c|c|c|c|c|c|c|c|c|c|c|}
\hline Reference & $n$ & CPT-EC & SSRT & Stroop & DS-T & DS-B & $\begin{array}{l}\text { SWM- } \\
\text { BSE }\end{array}$ & $\mathrm{SSp}$ & ToL & WCST & FAS & Categories \\
\hline Stevens et al. (2002) & $\begin{array}{l}\mathrm{ADHD}=76 \\
\mathrm{C}=76\end{array}$ & - & .34 & - & - & - & - & - & - & - & - & - \\
\hline Toplak et al. (2003) & $\begin{array}{l}\mathrm{ADHD}=59 \\
\mathrm{C}=39\end{array}$ & - & - & - & - & .7 & - & - & - & - & - & - \\
\hline Toplak et al. (2009) & $\begin{array}{l}\mathrm{ADHD}=45 \\
\mathrm{C}=42\end{array}$ & - & .58 & - & - & - & - & - & - & - & - & - \\
\hline Tripp and Alsop (1999) & $\begin{array}{l}\mathrm{ADHD}=43 \\
\mathrm{C}=19\end{array}$ & $.48^{\mathrm{b}}$ & - & - & - & - & - & - & - & - & - & - \\
\hline Tripp et al. (2002) & $\begin{array}{l}\mathrm{ADHD}=28 \\
\mathrm{C}=28\end{array}$ & $.15^{\mathrm{b}}$ & - & - & - & - & - & .9 & - & .69 & - & - \\
\hline Tsal et al. (2005) & $\begin{array}{l}\mathrm{ADHD}=27 \\
\mathrm{C}=15\end{array}$ & $.7^{\mathrm{b}}$ & - & - & - & - & - & - & - & - & - & - \\
\hline $\begin{array}{l}\text { van Leeuwen } \\
\text { et al. (1998) }\end{array}$ & $\begin{array}{l}\mathrm{ADHD}=20 \\
\mathrm{C}=20\end{array}$ & $1.27^{\mathrm{b}}$ & - & - & - & - & - & - & - & - & - & - \\
\hline Wiers et al. (1998) & $\begin{array}{l}\mathrm{ADHD}=28 \\
\mathrm{C}=34\end{array}$ & - & - & - & - & - & - & - & .33 & - & - & - \\
\hline Willcutt et al. (2005) & $\begin{array}{l}\mathrm{ADHD}=177 \\
\mathrm{C}=151\end{array}$ & $.49^{\mathrm{b}}$ & .57 & .07 & - & .59 & .55 & - & - & .43 & - & - \\
\hline Wu et al. (2002) & $\begin{array}{l}\mathrm{ADHD}=83 \\
\mathrm{C}=29\end{array}$ & - & - & - & - & .55 & - & - & .13 & - & - & - \\
\hline Mean weighted effect size & & .56 & .63 & .35 & .67 & .63 & .77 & .94 & .38 & .36 & .68 & .38 \\
\hline
\end{tabular}

$A D H D$ Attention Deficit Hyperactivity Disorder, $C$ Control group

CPT Continuous Performance Test, SSRT Stop Signal Reaction Time, DS-T Digit Span Total score, DS-B Digit Span Backwards, SWM-BSE Between-Search Errors on the CANTAB spatial working memory task, SSp Spatial Span, ToL Tower of London total score, WCST Wisconsin Card Sorting Task - perseverative errors, FAS F-A-S fluency task

${ }^{\mathrm{a}} \mathrm{CPT}$ - Inhibit to target

${ }^{\mathrm{b}} \mathrm{CPT}$ - Inhibit to non-target

${ }^{\mathrm{c}}$ All effect sizes presented as Cohen's $d$ (Cohen 1988), with positive effect sizes indicating ADHD performed worse on the task. Unbolded effect sizes $=$ ADHD group was not significantly different from controls. Bolded effect sizes $=$ ADHD group performed significantly worse than control

Similarly, four studies in the pediatric BD literature have explored $\mathrm{EC}$ on the $\mathrm{CPT}$ with an overall $\mathrm{ES}=.40$, which is somewhat less than in the ADHD literature, but also indicates a moderate effect for response inhibition difficulties. One of these studies found significant differences from control groups on CPT-EC ( $d=.69$; Pavuluri et al. 2006), while the other three did not (DelBello et al. 2004; Robertson et al. 2003; Rucklidge 2006). Two of these studies examined medication effects on EC and found no associated changes in performance (DelBello et al. 2004; Pavuluri et al. 2006).

One issue noted when reviewing the literature in both groups for the CPT, however, is that there is a difference in effect size for deficits on EC depending on whether the CPT involves inhibiting a prepotent response (i.e., inhibiting to a target stimulus; e.g., Conners 1985, 1992) or responding to a target (i.e., inhibiting to non-target stimuli; e.g., Gordon 1983; Rosvold et al. 1956), the latter of which some might classify as more a task of vigilance and sustained attention. In the ADHD literature, the average weighted effect size is much larger ( $\mathrm{ES}=.39$ versus .67$)$ for inhibiting to target versus nontarget. The same holds true for the BD literature $(\mathrm{ES}=.23$ versus .60). Thus, differences observed in these two diagnostic groups depend on CPT version (see Tables 3 and 4 for clarification on which CPT version was used in each study). Unfortunately, these versions are often combined in reviews.

The SST is also consistently associated with deficits in response inhibition in ADHD across the lifespan (Nigg 1999; Nigg et al. 2002; Rucklidge and Tannock 2002; Schachar et al. 2000). The average weighted effect size for studies reviewed was moderate to large $(\mathrm{ES}=.63)$. Nineteen out of 25 studies reviewed (76\%) found deficits in SSRT for children and adolescents with ADHD as compared to control groups. Those studies that did examine subtypes separately did not find effects of subtype on SSRT performance (Bedard et al. 2003; Geurts et al. 2004; Willcutt et al. 2005).

In the pediatric $\mathrm{BD}$ literature, three studies have examined deficits on SSRT and indicate a small effect $(\mathrm{ES}=.31)$. None of these studies found their BD groups to be significantly different than control groups (Leibenluft et al. 2007; McClure et al. 2005; Passarotti et al. 2009). The Passarotti study (2009), however, also directly compared 
Table 4 BD study effect sizes $(d)^{\mathrm{c}}$

\begin{tabular}{|c|c|c|c|c|c|c|c|c|c|c|c|c|}
\hline Reference & $n$ & CPT-EC & SSRT & Stroop & DS-T & DS-B & SWM-BSE & $\mathrm{SSp}$ & ToL & WCST & FAS & Categories \\
\hline Bearden et al. (2007) & $\begin{array}{l}\mathrm{BD}=31 \\
\mathrm{C}=44\end{array}$ & - & - & - & - & .38 & - & - & - & - & .34 & .46 \\
\hline Blumberg et al. (2003) & $\begin{array}{l}\mathrm{BD}=10 \\
\mathrm{C}=10\end{array}$ & - & - & .7 & - & - & - & - & - & - & - & - \\
\hline Castillo et al. (2000) & $\begin{array}{l}\mathrm{BD}=10 \\
\mathrm{C}=10\end{array}$ & - & - & - & - & - & - & - & .89 & - & - & - \\
\hline DelBello et al. (2004) & $\begin{array}{l}\mathrm{BD}=20 \\
\mathrm{C}=10\end{array}$ & $.48^{\mathrm{b}}$ & - & - & - & - & - & - & - & - & - & - \\
\hline Dickstein et al. (2004) & $\begin{array}{l}\mathrm{BD}=18 \\
\mathrm{C}=18\end{array}$ & - & - & - & - & - & .35 & - & - & - & - & - \\
\hline Doyle et al. (2005) & $\begin{array}{l}\mathrm{BD}=57 \\
\mathrm{C}=46\end{array}$ & - & - & .57 & .74 & - & - & - & - & .7 & - & - \\
\hline Leibenluft et al. (2007) & $\begin{array}{l}\mathrm{BD}=26 \\
\mathrm{C}=17\end{array}$ & - & .28 & - & - & - & - & - & - & - & - & - \\
\hline McClure et al. (2005) & $\begin{array}{l}\mathrm{BD}=38 \\
\mathrm{C}=22\end{array}$ & - & .49 & - & - & - & - & - & - & - & - & - \\
\hline Meyer et al. (2004) & $\begin{array}{l}\mathrm{BD}=9 \\
\mathrm{C}=54\end{array}$ & - & - & - & - & - & - & - & - & .6 & - & - \\
\hline Olvera et al. (2005) & $\begin{array}{l}\mathrm{BD}=28 \\
\mathrm{C}=16\end{array}$ & - & - & - & - & - & - & - & .98 & .89 & - & - \\
\hline Passarotti et al. (2009) & $\begin{array}{l}\mathrm{BD}=15 \\
\mathrm{C}=15\end{array}$ & - & .11 & - & - & - & - & - & - & - & - & - \\
\hline Pavuluri et al. (2006) & $\begin{array}{l}\mathrm{BD}=26 \\
\mathrm{C}=17\end{array}$ & $.69^{\mathrm{b}}$ & - & - & .43 & - & - & .91 & - & - & - & - \\
\hline Pavuluri et al. (2009a) & $\begin{array}{l}\mathrm{BD}=26 \\
\mathrm{C}=17\end{array}$ & - & - & - & .67 & - & - & .69 & - & - & - & - \\
\hline Robertson et al. (2003) & $\begin{array}{l}\mathrm{BD}=44 \\
\mathrm{C}=45\end{array}$ & $.2^{\mathrm{a}}$ & - & - & - & - & - & - & - & - & - & - \\
\hline Rucklidge (2006) & $\begin{array}{l}\mathrm{BD}=12 \\
\mathrm{C}=41\end{array}$ & $.35^{\mathrm{a}}$ & - & - & .84 & - & - & - & - & - & - & - \\
\hline Voelbel et al. (2006) & $\begin{array}{l}\mathrm{BD}=12 \\
\mathrm{C}=13\end{array}$ & - & - & .69 & - & - & - & - & - & .58 & .34 & .16 \\
\hline Mean weighted effect size & & .40 & .31 & .60 & .67 & .38 & .35 & .80 & .96 & .73 & .34 & .38 \\
\hline
\end{tabular}

$B D$ Bipolar Disorder, $C$ Control group

CPT Continuous Performance Test, SSRT Stop Signal Reaction Time, DS-T Digit Span Total score, DS-B Digit Span Backwards, SWM-BSE Between-Search Errors on the CANTAB spatial working memory task, SSp Spatial Span, ToL Tower of London total score, WCST Wisconsin Card Sorting Task - perseverative errors, FAS F-A-S fluency task

${ }^{\text {a }} \mathrm{CPT}$ - Inhibit to target

${ }^{\mathrm{b}} \mathrm{CPT}$ - Inhibit to non-target

${ }^{\mathrm{c}}$ All effect sizes presented as Cohen's $d$ (Cohen 1988), with positive effect sizes indicating BD performed worse on the task. Unbolded effect sizes $=$ BD group was not significantly different from controls. Bolded effect sizes $=$ BD group performed significantly worse than control.

the $\mathrm{BD}$ group to an ADHD group and found the ADHD group to have a faster SSRT, but this difference was not significant $(d=.37)$.

Thus, while some research focuses on the variable of errors of commission on the CPT as a neuropsychological representation of deficits in response inhibition in each of these disorders, performance on the SST is more consistently different from normal on the SST for ADHD. The two studies that directly compared pediatric BD to ADHD, however, found no significant differences between groups for CPT-EC (Rucklidge 2006) or SST (Passarotti et al. 2009). In sum, the evidence indicates the deficit in response inhibition to be present to some degree in both the ADHD and pediatric $\mathrm{BD}$ neurocognitive profiles.

\section{Interference Control}

The Stroop task (Stroop 1935) is a widely used measure of interference control that has been studied in both pediatric $\mathrm{BD}$ and ADHD samples, with the primary indicator being the interference score. Overall, Stroop interference in individuals with ADHD produces an overall small weighted effect size of .35. Ten out of 15 studies found no significant difference in Stroop interference performance for ADHD 
groups, with effect sizes ranging from .07 to .45 . The five studies that did find a significant difference in Stroop interference revealed medium to large effect sizes $(\mathrm{ES}=.31$ to 1.49; Barkley et al. 1992; Berlin et al. 2004; Grodzinsky and Diamond 1992; Lufi et al. 1990; Seidman et al. 1997b).

Three studies of pediatric BD literature have examined performance on the Stroop task, with a weighted effect size of .60. One study found children with BD trended towards difference on interference $(p=.07, \mathrm{ES}=.57 ; t$-scores $=49.0$ for BD and 52.9 for NC; Doyle et al. 2005). The remaining two studies in adolescents with $\mathrm{BD}$, however, did not find significant differences between BD and control groups on interference, although effect sizes were .7 and .69 (Blumberg et al. 2003; Voelbel et al. 2006).

Based on the data available to date, there is stronger evidence for interference control deficits on the Stroop task for individuals with BD than for those with ADHD. This may seem surprising given anecdotal evidence that individuals with ADHD are less able to inhibit distraction from external stimuli; however, these studies suggest that individuals with $\mathrm{BD}$ may have more difficulty ignoring unimportant stimuli during a task.

Overall, it appears that it is important to examine the subcomponents of inhibition when comparing $\mathrm{BD}$ and ADHD. These disorders show a similar pattern of deficits in response inhibition, which are either minor for CPTs requiring inhibition of a prepotent response or extensive for the SST. Difficulties with interference control, however, appear to be specific to BD.

\section{Working Memory}

\section{Verbal Working Memory}

Verbal working memory (VWM) is a component of executive function that involves the ability to manipulate incoming verbal information into organized output. The most widely used test of VWM is the Digit Span (DS) subtest of the Wechsler intelligence scales (WAIS, WISC; Wechsler 1991, 1994). It has two presentations, DS-Forward and DS-Backward, the latter of which is a robust indicator of executive function, requiring the manipulation of information in memory.

There is support for impairment on the DS-Backward for individuals with ADHD, with an average weighted effect size of .63. Five of 7 studies reporting performance on this subtest indicate that children with ADHD perform significantly worse than controls, with effect sizes ranging from .59 to 1.73 . Only two studies did not find deficits in performance on the DS-Backward task for children with ADHD (Barkley et al. 2001; Wu et al. 2002). Literature for DS-Backward is limited, however, in the pediatric BD area. Only one study has been conducted using this subtest, with results reflecting a small effect size of .38 with nonsignificant differences from the control sample (Bearden et al. 2007).

\section{Spatial Working Memory}

Spatial working memory (SWM) also involves the mental organization and manipulation of material but with nonverbal information. Several tasks are good representations of SWM, such as the Wechsler Spatial Span tasks and the SWM task from the Cambridge Neuropsychological Test Automated Battery (CANTAB; Luciana and Nelson 2002). As is the problem with DS, results of the Spatial Span task often combine forward and backward presentations, thus making it difficult to tease apart components of working memory (see Table 2 and Fig. 1).

Indications of deficits on the CANTAB SWM task for children with $\mathrm{ADHD}$, however, are consistent with those on VWM tasks (average weighted ES=.77). Five out of 7 studies found significant deficits in SWM on the CANTAB for children with ADHD. Two studies did not find impairment in ADHD on this task, with effect sizes ranging from .2 to .55 (Corbett et al. 2009; Willcutt et al. 2005). Again in pediatric BD only one study has examined SWM (CANTAB), and consistent with the VWM literature in this group, shows no deficits for pediatric $\mathrm{BD}$ ( $\mathrm{ES}=.35$; Dickstein et al. 2004).

Thus, overall, it appears that working memory impairments in both verbal and spatial domains may be emerging as a marker that differentiates ADHD from BD. Further research must be done to examine working memory specifically as its own domain and in further studies in pediatric BD.

As mentioned above, Wechsler digit and spatial span subtests are often presented as a composite score for the entire DS subtest. This is often the result of earlier versions of the WISC not separating the two, which can obscure important information regarding different components of executive control. As indicated in Table 2, the composite DS score (DS-Total) confounds the difference in working memory function between the two disorders, seen in DSBackwards. Several of the studies reviewed used the composite score, including 4 in the ADHD literature and 4 in the pediatric BD literature. Despite the confound result reporting, there is emerging evidence for deficits in working memory to be specific to ADHD.

\section{Planning}

Planning involves the ability to manipulate information into a reliable sequence that will achieve an end goal. It requires an individual not only to think in terms of the next step, but also to think of the future consequences of such a step. The task typically used to examine planning abilities across the pediatric BD and ADHD literature is the Tower of London (ToL; Shallice 1982). 
Results for the ToL indicate a small weighted effect size of .38 for deficits in ADHD. Four out of seven studies found no significant different in ToL total score from control groups (ES ranging from .13 to .36). Nigg et al. (2002) found children with ADHD-Combined type to have a lower total score on the ToL than controls. Similar findings have been reported in 2 other studies, although not classified by subtype (Kempton et al. 1999; Marzoochi et al. 2008).

Findings in the pediatric BD literature, although limited in number, more strongly indicate a planning deficit with a large weighted effect size of .96. Olvera et al. (2005) found youth with BD to perform significantly below the control group ( $\mathrm{ES}=.89$ ). With a younger sample, Castillo et al. (2000) found children with BD to perform below average on the NEPSY Tower subtest (mean scaled score $=7.17$ ).

While still preliminary based on the small number of studies in this domain, there is evidence for deficits in planning in pediatric BD as measured by the ToL. Furthermore, this dysfunction may be specific to the pediatric BD phenotype, but more research to directly examine this hypothesis needs to be executed.

\section{Set-Shifting}

Set-shifting is a process of working memory that involves attention to a current stimulus and the ability to maintain that attention while shifting between stimuli. The ability to adapt and change a response to new incoming stimuli in the environment has long been considered a hallmark of executive function. A measure of this dimension of executive function that spans the pediatric BD and ADHD literature is the perseverative errors score on the Wisconsin Card Sorting Test (WCST; Heaton 1981).

The findings for performance on the WCST for ADHD primarily indicate that children with ADHD do not show a deficit in set-shifting, with a small average weighted effect size of .36. Thirteen of 18 studies found no differences in perseverative errors and categories achieved between children with $\mathrm{ADHD}$ and controls ( $\mathrm{ES}=.07$ to .6). Five studies found children with ADHD made significantly more perseverative errors than controls, however, two studies reported a greater number of perseverative errors in their ADHD group, but noted that the difference became non-significant when they controlled for IQ, indicating that IQ may play a role in performance on the WCST (Tripp et al. 2002; Willcutt et al. 2005).

There is greater evidence for impairment on the WCST in pediatric $\mathrm{BD}$, with a large average weighted effect size of .73. Two out of 4 studies showed significant differences on the WCST from control groups $(\mathrm{ES}=.6$ and .89$)$, while 2 did not (ES=.58 and .7). Meyer et al. (2004) reported that young adults diagnosed with BD showed a trend toward more perseverative errors when the WCST was administered during their adolescence. Results of this study are important because early attentional problems in conjunction with disturbances in executive function on the WCST predicted BD onset, but not unipolar depression or no mood disorder in young adulthood. Thus, like deficits in planning, deficits in set-shifting appear to be specific to the pediatric BD phenotype.

\section{Verbal Fluency}

Fluency is a measure not only of vocabulary breadth and semantic memory, but also processing speed, working memory, inhibition, and set maintenance. Verbal fluency is often measured in two conditions: letters (phonemic) and categories (semantic). Perhaps the most widely used test of phonemic verbal fluency is the Controlled Oral Word Association Test (COWAT; Benton and Hamsher 1978), where individuals are required to generate words beginning with a particular letter (' $F$ ', 'A', or 'S'). For semantic fluency, individuals are required to generate particular items in a category within a given time.

Individuals with ADHD appear to have greater deficits with regard to phonemic fluency (weighted $\mathrm{ES}=.68$ ) than semantic fluency (weighted ES=.38). Deficits in phonemic fluency discriminate children with ADHD from controls better than semantic categories or designs (Barkley et al. 1992; Marzoochi et al. 2008; Mataró et al. 1997; Pineda et al. 1999). One study has reported deficits in both phonemic and semantic categories for children with ADHD (Geurts et al. 2004), whereas 3 report no difference from control groups on either domain of verbal fluency.

Importantly, the common comorbidity of ADHD and reading disability $(\mathrm{RD})$ has been shown to have additive effects for deficits in verbal fluency (Felton et al. 1987). Of the studies reviewed here, 3 excluded or accounted for RD in their analyses (Barkley et al. 1992; Loge et al. 1990; Marzoochi et al. 2008). The average weighted effect size for these studies continued to be large at 1.03 , providing evidence that deficits in phonemic fluency in children with ADHD are not limited to the comorbidity with RD.

Review of the pediatric BD literature indicates a small effect for dysfunction in either phonemic (weighted $\mathrm{ES}=.34$ ) or semantic fluency (weighted $\mathrm{ES}=.38$ ). Of the two studies that examined fluency thus far, one did not find deficits in either domain of verbal fluency for children with BD versus controls (Voelbel et al. 2006). The other study found significant differences in both domains, but further analysis indicated that medication accounted for the deficits in fluency (Bearden et al. 2007).

Thus, deficits in phonemic verbal fluency appear to be specific to ADHD and may be present over and above comorbidity with RD. Semantic fluency, however, does not appear to be associated with either ADHD or pediatric BD in any strong regard. 


\section{Discussion}

Although there appear to be some similarities between BD and ADHD in their neuropsychological function, subtle differences in various areas of executive function emerge as specific to each disorder. Overall, evidence exists for differences between neurocognitive profiles of pediatric BD and ADHD in several areas of executive function. The primary differences implicate impairments in interference control, planning, and set-shifting that are specific to $\mathrm{BD}$, and impairments in verbal and spatial working memory and phonemic verbal fluency that are specific to ADHD. Response inhibition does not appear to be distinctive in discriminating $\mathrm{BD}$ from $\mathrm{ADHD}$ at this time. Thus, evidence for distinctive profiles of executive function in these disorders exists.

There is evidence for a specific pattern of deficits in pediatric BD. While perhaps unexpected, similar to our findings, a meta-analysis conducted by van Mourik et al. (2005) concluded similarly that the Stroop task does not differentiate individuals with ADHD from controls well, despite differences in the calculation of interference scores. Similarly with planning and set-shifting abilities, our results provide evidence for deficits in this area particular to BD and markers that may be predictive of BD as opposed to other mood disorders (Meyer et al. 2004). Thus, an emerging profile of pediatric $\mathrm{BD}$ includes problems related to inhibiting distraction from irrelevant stimuli and having flexibility in thinking strategies.

Conversely, there is evidence for a specific profile for ADHD. Evidence indicates support for a deficit in both verbal and spatial domains of working memory in ADHD but not BD. Results from this review are consistent with a recent metaanalysis on correlates of executive function in ADHD (Willcutt et al. 2005), which supports an emerging theory of working memory deficit as a defining feature of ADHD. There is also a subtle difference between the two disorders within the domain of verbal fluency, with children with ADHD exhibiting deficits in phonemic fluency. This was found to be above and beyond contributions of comorbid reading disorders indicating that this may be a deficit inherent to ADHD and not simply a reflection of the comorbidity. This deficit in phonemic fluency is thus likely reflective of the inherent executive function profile emerging as specific to ADHD.

For the most part, the current review confirms findings from the adult literature in both BD and ADHD. Studies comparing BD adults to healthy control adults indicate that adults with BD have poorer interference scores on the Stroop (e.g., Balanzá-Martínez et al. 2005; Thompson et al. 2005), have poorer planning skills (e.g., Clark et al. 2001; Thompson et al. 2005), and make more perseverative errors on the WCST (e.g., Altshuler et al. 2004; Balanzá-Martínez et al. 2005). Studies in the adult BD literature also show deficits in verbal working memory and category fluency (e. g., Martínez-Arán et al. 2004; Thompson et al. 2005), indicating that performance in these facets of executive function may worsen during the course of the illness. Findings from the adult ADHD literature indicate that, similar to children, adults with ADHD show difficulty with working memory and phonemic fluency (Jenkins et al. 1998; Murphy et al. 2001; Seidman et al. 1998). With regard to response inhibition, one study is published indicating deficits in SSRT with in an adult BD sample as compared to a healthy control sample $(\mathrm{ES}=.52$; Strakowski et al. 2009). Findings for the CPT are in line with the pediatric BD literature indicating more impulsive response style (Altshuler et al. 2005; Tham et al. 1997; Wilder-Willis et al. 2001). Thus, more research is needed with the SST in BD samples before final conclusions are drawn.

\section{The Search for Potential Biomarkers}

With the advancement in neuroimaging techniques, evidence now exists to support the hypothesis that the tasks reviewed here elicit activity in the PFC. Interestingly, in areas of executive function for which differences between the two disorders exist, neurophysiological evidence supports the hypothesis that although the PFC is implicated in both $\mathrm{BD}$ and $\mathrm{ADHD}$, it functions differently in each disorder. On tasks of interference control and set-shifting, which are impaired in BD but not ADHD, neuroimaging studies have revealed increases in activation of the DLPFC for children with BD (Nelson et al. 2007), which is confirmed in adult studies of BD (Frey et al. 2005; Gruber et al. 2004; Michael et al. 2003). During working memory tasks, which are impaired in ADHD but not BD, the DLPFC and ventral PFC show blunted activation (Kobel et al. 2008). Interestingly, however, during a SWM task, Chang et al. (2004) found that children with BD showed greater activation of the left DLPFC, despite no significant difference in behavioral response. This follows the pattern of over-activation of the DLPFC and other areas of the PFC in $\mathrm{BD}$ and underactivation in ADHD during tasks of executive function. As noted earlier in this review, this pattern is found during response inhibition tasks (Passarotti et al. 2009). Thus, despite similar performance deficits on tasks of response inhibition, there are differing abnormalities in underlying neural networks. Thus, differences between BD and ADHD appear both behaviorally and physiologically during tasks of executive function, indicating that they are indeed separate disorders and can be measured objectively as such.

Implications

The differences in executive functioning in BD and ADHD may help to provide discriminant validity between these 
two disorders when they appear behaviorally similar in childhood by creating distinct neurocognitive profiles. Despite the encouraging results of this review, more research is needed in neurocognitive function in pediatric $\mathrm{BD}$ to confirm the findings. While the understanding of nosology is important, implications for correct differential diagnosis are imperative for clinical reasons. Treatments for these disorders differ radically, with ADHD utilizing stimulant medication (Greenhill et al. 2002) and behavioral parent training (Barkley 2002), and BD utilizing moodstabilizing medications (McClellan et al. 2007). Improper diagnosis can result in ADHD children being given medications, such as lithium, which are ineffective at treating symptoms of ADHD and have the potential for potent side effects (Giedd 2000). Additionally, a diagnosis of BD at a young age can have stigmatizing results, as it is a lifetime diagnosis with grave implications for functioning across the lifespan, such as hospitalizations, inability to retain employment, increased risk of substance abuse and suicide, and use of multiple medications throughout the lifespan (Birmaher and Axelson 2006; Chen and Dilsaver 1996; Goodwin and Jamison 1990). With additional research in pediatric BD, a future goal would be to bring these findings into the clinical realm to improve quality of care.

\section{Limitations}

One limitation of the bipolar literature on executive function is that the majority of studies do not follow individuals through the course of their illness. The adult BD literature indicates the cognitive abilities of individuals with $\mathrm{BD}$ can fluctuate with the presence or absence of an affective episode. For instance, impairments in sustained attention and impulsivity can be amplified during manic episodes (e.g., Sax et al. 1995), whereas Wilder-Willis et al. (2001) found that fine motor skills and reaction time remained impaired in a euthymic mood state. A longitudinal study found that individuals had impairment in serial learning on a verbal task while manic, but not when euthymic (Henry et al. 1973). In this same study, however, individuals showed no differences in impairment on shortterm free recall in various affective states. No recent studies, however, have been completed using a withinsubject design across mood states.

Rather than being viewed as a complication in assessing neurocognitive abilities in BD, these variations in cognitive abilities across mood states may prove to be a marker for differentiation between $\mathrm{BD}$ and ADHD. Cognition in ADHD appears to be relatively stable across the lifespan, with the exception of verbal working memory, which may improve later in life (Biederman et al. 1993). Given the number of studies conducted with youth of different ages, it appears that over a short period of time, the neurocognitive profile of ADHD is relatively stable. Thus, a potential method of differentiating between BD and ADHD may be to re-test individuals over a period of time, during which various mood states have the potential to occur and alter the testing results.

With the high rate of comorbidity reported between $\mathrm{BD}$ and ADHD in children, it is surprising that only one study was found directly comparing the neurocognitive aspects of these disorders in the absence of comorbidity. BD is often compared with schizophrenia or other severe psychopathology on cognitive tasks, whereas ADHD is most often compared with learning disabilities, oppositional defiant disorder, and conduct disorder. Clearly, if there is extensive comorbidity between these two disorders in youth as some of the literature has reported (Faraone et al. 1997; Geller et al. 2000; Geller et al. 2004; Wozniak et al. 1995), there is a need to examine not only the behavioral symptom presentations of each, but also the neurocognitive aspects as well.

Another limitation of this literature is the paucity of research on cognitive function in pediatric BD (see Tannock 1998). This field is only in its nascence, however, and it is encouraging to see numerous studies that have been published in the past 3 years examining neurocognition in pediatric BD samples. This paper is a preliminary examination of profiles of pediatric BD and further research is needed to confirm the findings here.

Additionally, there is the complicating factor of reading disorder (RD) comorbidity in ADHD. In a study conducted by Pennington et al. (1993), children with only ADHD exhibited deficits in executive function, but not in phonological processing, whereas children with only RD exhibited the opposite profile (deficits in phonological processing, but not executive function). One limitation of the current literature is that many studies did not control for comorbid RD. Several studies reviewed here examined phonemic fluency in ADHD in the absence of RD, with continued evidence for phonemic fluency dysfunction. Thus, while future studies will need to examine the F-A-S task in ADHD while controlling for the effects of a comorbid $\mathrm{RD}$ diagnosis, there is rising evidence that this deficit may not be solely explained by $\mathrm{RD}$ and may be particular to the ADHD phenotype.

\section{Conclusions}

Here we reviewed the literature and propose evidence for distinct neurocognitive profiles for BD and ADHD. Reports of comorbidity of childhood $\mathrm{BD}$ with $\mathrm{ADHD}$ range from 65-93\% (Faraone et al. 1997; Geller et al. 2000, 2004; Wozniak et al. 1995) in some studies, to $6-10 \%$ in others 
(Carlson 1998; Duffy et al. 2001; Kutcher et al. 1998; Robertson et al. 2003). Given the similar presentation of $\mathrm{BD}$ and $\mathrm{ADHD}$, it is often difficult to distinguish them from a purely clinical standpoint. Although more research needs to be conducted in the area of executive function, especially with regard to pediatric $\mathrm{BD}$, objective cognitive tasks in the context of a distinctive neurocognitive profile may provide insight into subtle differences between BD and ADHD when they are clinically indistinguishable.

Acknowledgements P. D. Walshaw is currently supported by a T32 (MH073517:01A1; McCracken and Piacentini, PIs) and was previously supported by a F31 (MH075292-01; Walshaw, PI). Research supported by the Center for Intervention and Development of Applied Research: Translational Research to Enhance Cognitive Control (P50 MH 077248-02; McCracken, PI). F. W. Sabb is supported by the Consortium for Neuropsychiatric Phenomics (UL1RR024911, RL1LM009833) and a NARSAD Young Investigator Award. L. B. Alloy's work on this article was supported by the National Institute of Mental Health Grants MH52617 and MH77908.

Disclosure No author has a financial relationship with the NIH, which sponsored this research. As this is a review paper the authors do not have access to the primary data of studies reviewed; access to the meta-data (e.g., effect sizes and calculations), however, can be provided.

Open Access This article is distributed under the terms of the Creative Commons Attribution Noncommercial License which permits any noncommercial use, distribution, and reproduction in any medium, provided the original author(s) and source are credited.

\section{References}

Alloway, T. P., Gathercole, S. E., Holmes, J., Place, M., Elliot, J. G., \& Hilton, K. (2009). The diagnostic utility of behavioral checklists in identifying children with ADHD and children with working memory deficits. Child Psychiatry and Human Development, 40, 353-366.

Altshuler, L. L., Bookheimer, S. Y., Townsend, J., Proenza, M. A., Eisenberger, N., Sabb, F., et al. (2005). Blunted activation in orbitofrontal cortex during mania: a functional magnetic resonance imaging study. Biological Psychiatry, 15, 763-769.

Altshuler, L. L., Ventura, J., van Gorp, W. G., Green, M. F., Theberge, D. C., \& Mintz, J. (2004). Neurocognitive function in clinically stable men with bipolar I disorder or schizophrenia and normal control subjects. Biological Psychiatry, 56, 560-569.

Assesmany, A., McIntosh, D. E., Phelps, L., \& Rizza, M. G. (2001). Discriminant validity of the WISC-III with children classified as ADHD. Journal of Psychoeducational Assessment, 19, 137-147.

Axelson, D., Birmaher, B., Strober, M., Gill, M. K., Valeri, S., et al. (2006). Phenomenology of children and adolescents with bipolar disorder. Archives of General Psychiatry, 63, 1139-1148.

Balanzá-Martínez, V., Tabarés-Seisdedos, R., Selva-Vera, G., MartínezArán, A., Torrent, C., Salazar-Fraile, J., et al. (2005). Persistent cognitive dysfunctions in bipolar I disorder and schizophrenic patients: a 3-year follow-up study. Psychotherapy and Psychosomatics, 74, 113-119.

Barkley, R. A. (1997). Behavioral inhibition, sustained attention, and executive functions: constructing a unifying theory of ADHD. Psychological Bulletin, 121, 65-94.
Barkley, R. A. (2002). Psychosocial treatments for attention-deficit/ hyperactivity disorder in children. Journal of Clinical Psychiatry, $63,36-43$.

Barkley, R. A., Edwards, G., Laneri, M., Fletcher, K., \& Metevia, L. (2001). Executive functioning, temporal discounting, and sense of time in adolescents with attention deficit hyperactivity disorder (ADHD) and oppositional defiant disorder (ODD). Journal of Abnormal Child Psychology, 29, 541-556.

Barkley, R. A., \& Grodzinsky, G. M. (1994). Are tests of frontal lobe functions useful in the diagnosis of attention deficit disorders? The Clinical Neuropsychologist, 8, 121-139.

Barkley, R. A., Grodzinsky, G. M., \& DuPaul, G. (1992). Frontal lobe functions in attention deficit disorder with and without hyperactivity: a review and research report. Journal of Abnormal Child Psychology, 20, 163-188.

Barnett, R., Maruff, P., Vance, A., Luk, E. S. L., Costin, J., Wood, C., et al. (2001). Abnormal executive function in attention deficit hyperactivity disorder: the effect of stimulant medication and age on spatial working memory. Psychological Medicine, 31, 11071115

Bearden, C. E., Glahn, D. C., Caetano, S., Olvera, R. L., Fonseca, M., Najt, P., et al. (2007). Evidence for disruption in prefrontal cortical functions in juvenile bipolar disorder. Bipolar Disorders, 9, 145-151.

Bearden, C. E., Hoffman, K. M., \& Cannon, T. D. (2001). The neuropsychology and neuroanatomy of bipolar affective disorder: a critical review. Bipolar Disorders, 3, 106-150.

Bedard, A., Ickowitz, A., Logan, G. D., Hogg-Johnson, S., Schachar, R., \& Tannock, R. (2003). Selective inhibition in children with attention-deficit hyperactivity disorder off and on stimulant medication. Journal of Abnormal Child Psychology, 31, 315-327.

Benton, A. L., \& deS Hamsher, K. (1978). Multilingual aphasia examination-revised. Iowa: University of Iowa.

Berlin, L., Bohlin, G., Nyberg, L., \& Janols, L. (2004). How well do measures of inhibition and other executive functions discriminate between children with ADHD and controls? Child Neuropsychology, 10, 1-13.

Biederman, J., Faraone, S. V., Spencer, T., Wilens, T., Norman, D., Lapey, K. A., et al. (1993). Patterns of psychiatric comorbidity, cognition, and psychosocial functioning in adults with attention deficit hyperactivity disorder. American Journal of Psychiatry, 150, 1792-1798.

Birmaher, B., \& Axelson, D. (2006). Course and outcome of bipolar spectrum disorder in children and adolescents: a review of the existing literature. Development and Psychopathology, 18, 10231035.

Blumberg, H. P., Fredericks, C., Wang, F., Kalmar, J. H., Spencer, L., Papademetris, X., et al. (2005). Preliminary evidence for persistent abnormalities in amygala volumes in adolescents and young adults with bipolar disorder. Bipolar Disorders, 7, 570 576.

Blumberg, H. P., Martin, A., Kaufman, J., Leung, H., Skudlarski, P., Lacadie, C., et al. (2003). Frontostriatal abnormalities in adolescents with bipolar disorder: preliminary observations from functional MRI. American Journal of Psychiatry, 160, 1345-1347.

Borger, N., van der Meere, J., Ronner, A., Alberts, E., Geuze, R., \& Bogte, H. (1999). Heart rate variability and sustained attention in ADHD children. Journal of Abnormal Child Psychology, 27, 25-33.

Brewer, V. R., Fletcher, J. M., Hiscock, M., \& Davidson, K. C. (2001). Attention processes in children with shunted hydrocephalus versus attention-deficit hyperactivity disorder. Neuropsychology, 15, 185-198.

Cairney, S., Maruff, P., Vance, A., Barnett, R., Luk, E., \& Currie, J. (2001). Contextual abnormalities of saccadic inhibition in children with attention deficit hyperactivity disorder. Experimental Brain Research, 141, 507-518. 
Carlson, G. A. (1998). Mania and ADHD: comorbidity or confusion. Journal of Affective Disorders, 51, 177-187.

Casey, B. J., Castellanos, F. X., Giedd, J. N., Marsh, W. L., Hamburger, S. D., Shubert, A. B., et al. (1997). Implication of right frontostriatal circuitry in response inhibition and attention-deficit/ hyperactivity disorder. Journal of the American Academy of Child and Adolescent Psychiatry, 36, 374-383.

Castillo, M., Kwock, L., Courvoisie, H., \& Hooper, S. R. (2000). Proton MR spectroscopy in children with bipolar affective disorder: preliminary observations. AJNR American Journal of Neuroradiology, 21, 832-838.

Chang, K., Adelman, N. E., Dienes, K., Simeonova, D. I., Menon, V., \& Reiss, A. (2004). Anomalous prefrontal-subcortical activation in familial pediatric bipolar disorder. Archives of General Psychiatry, 61, 781-792.

Chen, Y.-W., \& Dilsaver, S. C. (1996). Lifetime rates of suicide attempts among subjects with bipolar and unipolar disorders relative to subjects with other axis I disorders. Society of Biological Psychiatry, 39, 896-899.

Clark, L., Iversen, S. D., \& Goodwin, G. M. (2001). A neuropsychological investigation of prefrontal cortex involvement in acute mania. American Journal of Psychiatry, 158, 1605-1611.

Cohen, J. (1988). Statistical power analysis for the behavioral sciences (2nd ed.). Hillsdale: Erlbaum.

Collings, R. D. (2003). Differences between ADHD inattentive and combined types on the CPT. Journal of Psychopathology and Behavioral Assessment, 25, 177-189.

Conners, C. K. (1985). The computerized continuous performance test. Psychopharmacological Bulletin, 21, 891-892.

Conners, C. K. (1992). Continuous Performance Test computer program, version 2.0. North Tonawanda: Multi-Health Systems.

Corbett, B. A., Constantine, L. J., Hendren, R., Rocke, D., \& Ozonoff, S. (2009). Examining executive functioning in children with autism spectrum disorder, attention deficit hyperactivity disorder and typical development. Psychiatry Research, 166, 210-222.

DelBello, M. P., Adler, C. M., Amicone, J., Mills, N. P., Shear, P. K., Warner, J., et al. (2004). Parametric neurocognitive task design: a pilot study of sustained attention in adolescents with bipolar disorder. Journal of Affective Disorders, 82S, S79-S88.

Dickstein, D. P., Treland, J. E., Snow, J., McClure, E. B., Mehta, M. S., Towbin, K. E., et al. (2004). Neuropsychological performance in pediatric bipolar disorder. Biological Psychiatry, 55, 32-39.

Dimoska, A., Johnstone, S. J., Barry, R. J., \& Clarke, A. R. (2003). Inhibitory motor control in children with attention-deficit/ hyperactivity disorder: event-related potentials in the stop-signal paradigm. Biological Psychiatry, 54, 1345-1354.

Doyle, A. E., Wilens, T. E., Kwon, A., Seidman, L. J., Faraone, S. V., Fried, R., et al. (2005). Neuropsychological functioning in youth with bipolar disorder. Biological Psychiatry, 58, 540-548.

Duffy, A., Gropf, P., Kutcher, S., Robertson, C., \& Alda, M. (2001). Measures of attention and hyperactivity symptoms in a high-risk sample of children of bipolar parents. Journal of Affective Disorders, 67, 159-165.

Epstein, J. N., Erkanli, A., Conners, C. K., Klaric, J., Costello, J. E., \& Angold, A. (2003). Relations between continuous performance test performance measures and ADHD behavior. Journal of Abnormal Child Psychology, 31, 543-554.

Faraone, S. V., Biederman, J., Wozniak, J., Mundy, E., Mennin, D., \& O'Donnell, D. (1997). Is comorbidity with ADHD a marker for juvenile-onset mania? Journal of the American Academy of Child and Adolescent Psychiatry, 36, 1046-1055.

Felton, R. H., Wood, F. B., Brown, I. S., \& Campbell, S. K. (1987). Separate verbal memory and naming deficits in attention deficit disorder and reading disability. Brain and Language, 31, 171-184.

Frey, B. N., Folgierini, M., Nicoletti, M., Machado-Vieira, R., Stanley, J. A., Soares, J. C., et al. (2005). A proton magnetic resonance spectroscopy investigation of the dorsolateral prefrontal cortex in acute mania. Human Psychopharmacology, 20, 133-139.

Galantar, C. A., \& Leibenluft, E. (2008). Frontiers between attention deficit hyperactivity disorder and bipolar disorder. Child and Adolescent Psychiatric Clinics of North America, 17, 325-346.

Geller, B., Tillman, R., Craney, J. L., \& Bolhofner, K. (2004). Fouryear prospective outcome and natural history of mania in children with a prepubertal and early adolescent bipolar disorder phenotype. Archives of General Psychiatry, 61, 459-467.

Geller, B., Zimerman, B., Williams, M., Bolhofner, K., Craney, J. L., DelBello, M. P., et al. (2000). Six-month stability and outcome of a prepubertal and early adolescent bipolar disorder phenotype. Journal of Child and Adolescent Psychopharmacology, 10, 165-173.

Geller, B., Zimerman, B., Williams, M., DelBello, M. P., Bolhofner, K., et al. (2002). DSM-IV mania symptoms in a prepubertal and early adolescent bipolar disorder phenotype compared to attention-deficit hyperactive and normal controls. Journal of Child and Adolescent Psychopharmacology, 12, 11-23.

Geurts, H. M., Verte, S., Oosterlaan, J., Roeyers, H., \& Sergeant, J. A. (2004). How specific are executive functioning deficits in attention deficit hyperactivity disorder and autism? Journal of Child Psychology and Psychiatry, 45, 836-854.

Giedd, J. N. (2000). Bipolar disorder and attention-deficit/hyperactivity disorder in children and adolescents. Journal of Clinical Psychiatry, 61, 31-34.

Goldberg, M. C., Mostofsky, S. H., Cutting, L. E., Mahone, E. M., Astor, B. C., Denckla, M. B., et al. (2005). Subtle executive impairment in children with autism and children with ADHD. Journal of Autism and Developmental Disorders, 35, 279-293.

Goodwin, F. K., \& Jamison, K. R. (1990). Manic-depressive illness. London: Oxford University Press.

Gordon, M. (1983). The Gordon diagnostic system. DeWitt: Gordon Systems.

Greenhill, L. L., Pliszka, S., Dulcan, M. K., Bernet, W., Arnold, V., Beitchman, J., et al. (2002). Practice parameter for the use of stimulant medications in the treatment of children, adolescents, and adults. Journal of the American Academy of Child and Adolescent Psychiatry, 41, 26S-49S.

Grodzinsky, G. M., \& Diamond, R. (1992). Frontal lobe functioning in boys with attention-deficit hyperactivity disorder. Developmental Neuropsychology, 8, 427-445.

Gruber, S. A., Rogowska, J., \& Yurgelun-Todd, D. A. (2004). Decreased activation of the anterior cingulate in bipolar patients: an fMRI study. Journal of Affective Disorders, 82, 191-201.

Happe, F., Booth, R., Charlton, R., \& Hughes, C. (2006). Executive function deficits in autistic spectrum disorders and attentiondeficit/hyperactivity disorder: examining profiles across domains and ages. Brain and Cognition, 61, 25-39.

Heaton, R. K. (1981). Wisconsin cart sorting test manual. Odessa: Psychological Assessment Resource Inc.

Henin, A., Mick, E., Biederman, J., Fried, R., Wozniak, J., Faraone, S. V., et al. (2007). Can bipolar disorder-specific neuropsychological impairments in children be identified? Journal of Consulting and Clinical Psychology, 75, 210-220.

Henry, G. M., Weingartner, H., \& Murphy, D. L. (1973). Influence of affective states and psychoactive drugs on verbal learning and memory. American Journal of Psychiatry, 130, 966-971.

Horn, W. F., Wagner, A. E., \& Ialongo, N. (1989). Sex differences in school-aged children with pervasive attention deficit hyperactivity disorder. Journal of Abnormal Child Psychology, 17, 109-125.

Houghton, S., Douglas, G., West, J., Whiting, K., Wall, M., Langsford, S., et al. (1999). Differential patterns of executive function in children with attention-deficit hyperactivity disorder according to gender and subtype. Journal of Child Neurology, 14, 801-805.

Jenkins, M., Cohen, R., Malloy, P., Salloway, S., Johnson, E. G., Penn, J., et al. (1998). Neuropsychological measures which 
discriminate among adults with residual symptoms of attention deficit disorder and other attentional complaints. The Clinical Neuropsychologist, 12, 74-83.

Jennings, J. R., van der Molen, M. W., Pelham, W., Debski, K. B., \& Hoza, B. (1997). Inhibition in boys with attention deficit hyperactivity disorder as indexed by heart rate change. Developmental Psychology, 33, 308-318.

Kalmar, J. H., Wang, F., Spencer, L., Edmiston, E., Lacadie, C. M., Martin, A., et al. (2009). Preliminary evidence for progressive prefrontal abnormalities in adolescents and young adults with bipolar disorder. Journal of the International Neuropsychological Society, 15, 476-481.

Kempton, S., Vance, A., Maruff, P., Luk, E., Costin, J., \& Pantelis, C. (1999). Executive function and attention deficit hyperactivity disorder: stimulant medication and better executive function performance in children. Psychological Medicine, 29, 527-538.

Kent, L., \& Craddock, N. (2003). Is there a relationship between bipolar disorder and attention deficit hyperactivity disorder? Journal of Affective Disorders, 73, 211-221.

Kerns, K. A., McInerney, R. J., \& Wilde, N. J. (2001). Time reproduction, working memory, and behavioral inhibition in children with ADHD. Child Neuropsychology, 7, 21-31.

Klorman, R., Hazel-Fernandez, L. A., Shaywitz, S. E., Fletcher, J. M., Marchione, K. E., Holahan, J. M., et al. (1999). Executive functioning deficits in attention-deficit/hyperactivity disorder are independent of oppositional defiant or reading disorder. Journal of the American Academy of Child and Adolescent Psychiatry, $38,1148-1155$.

Kobel, M., Bechtel, N., Weber, P., Specht, K., Klarhofer, M., et al. (2008). Effects of methylphenidate on working memory functioning in children with attention deficit/hyperactivity disorder. Journal of the European Paediatric Neurology Society, 13, 516523.

Konrad, K., Gauggel, S., Manz, A., \& Schöll, M. (2000). Lack of inhibition: a motivational deficit in children with attention deficit/ hyperactivity disorder and children with traumatic brain injury. Child Neuropsychology, 6, 286-296.

Konrad, K., Neufang, S., Fink, G. R., \& Herpertz-Dalhmann, B. (2007). Long-term effects of methylphenidate on neural networks associated with executive attention in children with ADHD: results from a longitudinal functional MRI study. Journal of the American Academy of Child and Adolescent Psychiatry, 46, 1633-1641.

Kutcher, S., Robertson, H. A., \& Bird, D. (1998). Premorbid functioning in adolescent onset bipolar I disorder: a preliminary report from an ongoing study. Journal of Affective Disorders, 51, $137-144$.

Lawrence, V., Houghton, S., Douglas, G., Durkin, K., Whiting, K., \& Tannock, R. (2004). Executive function and ADHD: a comparison of children's performance during neuropsychological testing and real-world activities. Journal of Attention Disorders, 7, 137149.

Leibenluft, E., \& Rich, B. A. (2008). Pediatric bipolar disorder. Annual Review of Clinical Psychology, 4, 163-187.

Leibenluft, E., Rich, B. A., Vinton, D. T., Nelson, E. E., Fromm, S. J., Berghorst, L. H., et al. (2007). Neural circuitry engaged during unsuccessful motor inhibition in pediatric bipolar disorder. American Journal of Psychiatry, 164, 52-60.

Logan, G. D., Cowan, W. B., \& Davis, K. A. (1984). On the ability to inhibit thought and action: a model and a method. Journal of Experimental Psychology, 10, 276-291.

Loge, D. V., Staton, R. D., \& Beatty, W. W. (1990). Performance of children with ADHD on tests sensitive to frontal lobe dysfunction. Journal of the American Academy of Child and Adolescent Psychiatry, 29, 540-545.

Lopez-Larson, M., Michael, E. S., Terry, J. E., Breeze, J. L., Hodge, S. M., Tang, L., et al. (2009). Subcortical differences among youths with attention-deficit/hyperactivity disorder compared to those with bipolar disorder with and without attention-deficit/hyperactivity disorder. Journal of Child and Adolescent Psychopharmacology, 19, 31-39.

Luciana, M., \& Nelson, C. A. (2002). Assessment of neuropsychological function through use of the Cambridge Neuropsychological Testing Automated Battery: performance in 4- to 12-year-old children. Developmental Neuropsychology, 22, 595-624.

Lufi, D., Cohen, A., \& Parish-Plass, J. (1990). Identifying attention deficit hyperactive disorder with the WISC-R and the Stroop color and word test. Psychology in the Schools, 27, 28-34.

Manassis, K., Tannock, R., \& Barbosa, J. (2000). Dichotic listening and response inhibition in children with comorbid anxiety disorders and ADHD. Journal of the American Academy of Child and Adolescent Psychiatry, 39, 1152-1159.

Mariani, M. A., \& Barkley, R. A. (1997). Neuropsychological and academic functioning in preschool boys with attention deficit hyperactivity disorder. Developmental Neuropsychology, 13, 111-129.

Martínez-Arán, A., Vieta, E., Reinares, M., Colom, F., Torrent, C., Sánchez-Moreno, J., et al. (2004). Cognitive function across manic or hypomanic, depressed, and euthymic states in bipolar disorder. American Journal of Psychiatry, 161, 262-270.

Marzoochi, G. M., Oosterlaan, J., Zuddas, A., Cavolina, P., Geurts, H., Redigolo, D., et al. (2008). Contrasting deficits on executive functions between ADHD and reading disabled children. Journal of Child Psychology and Psychiatry, 49, 543-552.

Mataró, M., García-Sánchez, C., Junqué, C., Estévez-González, A., \& Pujol, J. (1997). Magnetic resonance imaging measurement of the caudate nucleus in adolescents with attention-deficit hyperactivity disorder and its relationship with neuropsychological and behavioral measures. Archives of Neurology, 54, 963-968.

McClellan, J., Kowatch, R., Findling, R. L., \& Work Group on Quality Issues. (2007). Practice parameter for the assessment and treatment of children and adolescents with bipolar disorder. Journal of the American Academy of Child and Adolescent Psychiatry, 46, 107-125.

McClure, E. B., Treland, J. E., Snow, J., Schmajuk, M., Dickstein, D. P., Towbin, K. E., et al. (2005). Deficits in social cognition and response flexibility in pediatric bipolar disorder. American Journal of Psychiatry, 162, 1644-1651.

McInerney, R. J., \& Kerns, K. A. (2003). Time reproduction in children with ADHD: motivation matters. Child Neuropsychology, 9, 91-108.

McInnes, A., Humphries, T., Hogg-Johnson, S., \& Tannock, R. (2003). Listening comprehension and working memory are impaired in attention-deficit/hyperactivity disorder irrespective of language impairment. Journal of Abnormal Child Psychology, 31, 427-443.

Meyer, S. E., Carlson, G. A., Wiggs, E. A., Martinez, P. E., Ronsaville, D. S., Klimes-Dougan, B., et al. (2004). A prospective study of the association among impaired executive functioning, childhood attentional problems, and the development of bipolar disorder. Development and Psychopathology, 16, 461-476.

Michael, N., Erfurth, A., Ohrmann, P., Gössling, M., Arolt, V., Heindel, W., et al. (2003). Acute mania is accompanied by elevated glutamate/glutamine levels within the left dorsolateral prefrontal cortex. Psychopharmacology, 168, 344-346.

Murphy, K. R., Barkley, R. A., \& Bush, T. (2001). Executive functioning and olfactory identification in young adults with attention deficithyperactivity disorder. Neuropsychology, 15, 211-220.

National Institute of Mental Health research roundtable on prepubertal bipolar disorder. (2001). Journal of the American Academy of Child and Adolescent Psychiatry, 40(8), 871-878.

Nelson, E. E., Vinton, D. T., Berghorst, L., Towbin, K. E., Hommer, R. E., Dickstein, D. P., et al. (2007). Brain systems underlying response flexibility in healthy and bipolar adolescents: an eventrelated fMRI study. Bipolar Disorders, 9, 810-819. 
Nigg, J. T. (1999). The ADHD response-inhibition deficit as measured by the stop task: replication with DSM-IV combined type, extension, and qualification. Journal of Abnormal Child Psychology, 27, 393-402.

Nigg, J. T. (2000). On inhibition/disinhibition in developmental psychopathology: views from cognitive and personality psychology and a working inhibition taxonomy. Psychological Bulletin, $126,220-246$.

Nigg, J. T., Blaskey, L. G., Huang-Pollock, C. L., \& Rappley, M. D. (2002). Neuropsychological executive functions and DSM-IV ADHD subtypes. Journal of the American Academy of Child and Adolescent Psychiatry, 41, 59-66.

Olvera, R. L., Semrud-Clikeman, M., Pliszka, S. R., \& O’Donnell, L. (2005). Neuropsychological deficits in adolescents with conduct disorder and comorbid bipolar disorder: a pilot study. Bipolar Disorders, 7, 57-67.

Overtoom, C. C. E., Kenemans, J. L., Verbaten, M. N., Kemner, C., van der Molen, M. W., van Engeland, H., et al. (2002). Inhibition in children with attention-deficit/hyperactivity disorder: a psychophysiological study of the stop task. Biological Psychiatry, 51, 668-676.

Passarotti, A. M., Sweeney, J. A., \& Pavuluri, M. N. (2009). Neural correlates of response inhibition in pediatric bipolar disorder and attention deficit hyperactivity disorder. Psychiatry Research: Neuroimaging, 4, 397-398.

Pavuluri, M. N., Schenkel, L. S., Aryal, S., Harral, E. M., Hill, S. K., Herbener, E. S., et al. (2006). Neurocognitive function in unmedicated manic and medicated euthymic pediatric bipolar patients. American Journal of Psychiatry, 163, 286-293.

Pavuluri, M. N., West, A., Hill, S. K., Jindal, K., \& Sweeney, J. A. (2009a). Neurocognitive function in pediatric bipolar disorder: 3 year follow-up shows cognitive development lagging behind healthy youths. Journal of the American Academy of Child and Adolescent Psychiatry, 48, 299-307.

Pavuluri, M. N., Yang, S., Kamineni, K., Passarotti, A. M., GSrinivasan, G., Harral, E. M., et al. (2009b). Diffusion tensor imaging study of white matter fiber tracts in pediatric bipolar disorder and attention-deficit/hyperactivity disorder. Biological Psychiatry, 65, 586-593.

Pennington, B. F. (1997). Dimensions of executive function in normal and abnormal development. In N. A. Krasnegor, G. R. Lyon, \& P. S. Goldman-Rakic (Eds.), Development of the prefrontal cortex (pp. 265-281). Baltimore: Brookes.

Pennington, B. F., Bennetto, L., McAleer, O. K., \& Roberts, R. J., Jr. (1996). Executive functions and working memory: Theoretical and measurement issues. In G. R. Lyon \& N. A. Krasnegor (Eds.), Attention, memory, and executive function (pp. 327-348). Baltimore: Brookes.

Pennington, B. F., Grossier, D., \& Welsh, M. C. (1993). Contrasting cognitive deficits in attention deficit hyperactivity disorder versus reading disability. Developmental Psychology, 29, 511-523.

Pineda, D., Ardila, A., \& Rosselli, M. (1999). Neuropsychological and behavioral assessment of ADHD in seven- to twelve-year-old children. Journal of Learning Disabilities, 32, 159-173.

Pliszka, S. R. (1992). Comorbidity of attention deficit hyperactivity disorder and overanxious disorder. Journal of the American Academy of Child and Adolescent Psychiatry, 31, 197-209.

Pliszka, S. R., Borcherding, S. H., Spratley, K., Leon, S., \& Irick, S. (1997). Measuring inhibitory control in children. Journal of Developemental and Behavioral Pediatrics, 18, 254-259.

Pliszka, S. R., Liotti, M., \& Woldorff, M. G. (2000). Inhibitory control in children with attention-deficit/hyperactivity disorder: event related potentials identify the processing component and timing of an impaired right-frontal response-inhibition mechanism. Biological Psychiatry, 48, 238-246.

Purvis, K., \& Tannock, R. T. (2000). Phonological processing, not inhibitory control, differentiates ADHD and reading disorder.
Journal of the American Academy of Child and Adolescent Psychiatry, 39, 485-494.

Quay, H. C. (1988). Attention deficit disorder and the behavioral inhibition system: The relevance of the neuropsychological theory of Jeffrey A. Gray. In L. M. Bloomingdale \& J. Sergeant (Eds.), Attention deficit disorder: Criteria, cognition, intervention (pp. 117-125). Oxford: Pergamon.

Quay, H. C. (1997). Inhibition and attention deficit hyperactivity disorder. Journal of Abnormal Child Psychology, 25, 7-13.

Rich, B. A., Schmajuk, M., Perez-Edgar, K. E., Fox, N. A., Pine, D. S., \& Liebenluft, E. (2007). Different psychophysiological and behavioral responses elicited by frustration in pediatric bipolar disorder and severe mood dysregulation. American Journal of Psychiatry, 164, 309-317.

Robertson, H. A., Kutcher, S. P., \& Lagace, D. C. (2003). No evidence of attentional deficits in stabilized bipolar youth relative to unipolar and control comparators. Bipolar Disorders, 5, 330339.

Rosvold, H. E., Mirsky, A. F., Sarason, I., Bransome, E. D., \& Beck, L. H. (1956). A continuous performance test of brain damage. Journal of Consulting Psychology, 20, 343-352.

Rubia, K., Taylor, E., Smith, A. B., Oksannen, H., Overmeyer, S., \& Newman, S. (2001). Neuropsychological analyses of impulsiveness in childhood hyperactivity. British Journal of Psychiatry, $179,138-143$.

Rucklidge, J. J. (2006). Impact of ADHD on the neurocognitive functioning of adolescents with bipolar disorder. Biological Psychiatry, 60, 921-928.

Rucklidge, J. J., \& Tannock, R. (2002). Neuropsychological profiles of adolescents with ADHD: effects of reading difficulties and gender. Journal of Child Psychology and Psychiatry, 43, 9881003.

Sabb, F. W., Bearden, C. E., Glahn, D. C., Parker, D. S., Friemer, N., \& Bilder, R. M. (2008). A collaborative knowledge base for cognitive phenomics. Molecular Psychiatry, 13, 350-360.

Sartory, G., Heine, A., Müller, B. W., \& Elvermann-Hallner, A. (2002). Event- and motor-related potentials during the continuous performance task in attention-deficit/hyperactivity disorder. Journal of Psychophysiology, 16, 97-106.

Sax, K. W., Strakowski, S. M., McElroy, S. L., Keck, P. E., Jr., \& West, S. A. (1995). Attention and formal thought disorder in mixed and pure mania. Biological Psychiatry, 37, 420-423.

Schachar, R., \& Logan, G. D. (1990). Impulsivity and inhibitory control in normal development and childhood psychopathology. Developmental Psychology, 26, 710-720.

Schachar, R., Mota, V. L., Logan, G. D., Tannock, R., \& Klim, P. (2000). Confirmation of an inhibitory control deficit in attentiondeficit/hyperactivity disorder. Journal of Abnormal Child Psychology, 28, 227-235.

Schachar, R., \& Tannock, R. (1995). Test of four hypotheses for the comorbidity of attention deficit hyperactivity disorder and conduct disorder. Journal of the American Academy of Child and Adolescent Psychiatry, 34, 639-648.

Schachar, R. J., Tannock, R., Marriott, M., \& Logan, G. (1995). Control of response processes in attention deficit hyperactivity disorder. Journal of Abnormal Child Psychology, 23, 411-437.

Scheres, A., Oosterlaan, J., \& Sergeant, J. A. (2001). Response execution and inhibition in children with $\mathrm{AD} / \mathrm{HD}$ and other disruptive disorders: The role of behavioural activation. Journal of Child Psychology and Psychiatry, 42, 347-357.

Schmitz, M., Cadore, L., Paezko, M., Kipper, L., Chaves, M., Rohde, L. A., et al. (2002). Neuropsychological performance in DSM-IV ADHD subtypes: an exploratory study with untreated adolescents. Canadian Journal of Psychiatry, 47, 863-869.

Seidman, L. J., Biederman, J., Faraone, S. V., Weber, W., Mennin, D., \& Jones, J. (1997a). A pilot study of neuropsychological function 
in girls with ADHD. Journal of the American Academy of Child and Adolescent Psychiatry, 36, 366-373.

Seidman, L. J., Biederman, J., Faraone, S. V., Weber, W., \& Ouellette, C. (1997b). Toward defining a neuropsychology of attention deficit-hyperactivity disorder: performance of children and adolescents from a large clinically referred sample. Journal of Consulting and Clinical Psychology, 65, 150-160.

Seidman, L. J., Biederman, J., Weber, W., Hatch, M., \& Faraone, S. V. (1998). Neuropsychological function in adults with attentiondeficit hyperactivity disorder. Biological Psychiatry, 44, 260-268.

Shallice, T. (1982). Specific impairments of planning. Philosophical Transactions of Royal Society of London B: Biological Science, 298, 199-209.

Shue, K. L., \& Douglas, V. I. (1992). Attention deficit hyperactivity disorder and the frontal lobe syndrome. Brain and Cognition, 20, 104-124.

Smith, A. B., Taylor, E., Brammer, M., Halari, R., \& Rubia, K. (2008). Reduced activation in right lateral prefrontal cortex and anterior cingulate gyurs in medication-naïve adolescents with attention deficit hyperactivity disorder during time discrimination. Journal of Child Psychology and Psychiatry, 49, 977-985.

Solanto, M. V., Abikoff, H., Sonuga-Barke, E., Schachar, R., Logan, G. D., Wigal, T., et al. (2001). The ecological validity of delay aversion and response inhibition as measures of impulsivity in AD/HD: a supplement to the NIMH multimodal treatment study of AD/HD. Journal of Abnormal Child Psychology, 29, 215-228.

Stevens, J., Quittner, A. L., Zuckerman, J. B., \& Moore, S. (2002). Behavioral inhibition, self-regulation of motivation, and working memory in children with attention deficit hyperactivity disorder. Developmental Neuropsychology, 21, 117-139.

Strakowski, S. M., Fleck, D. E., DelBello, M. P., Adler, C. M., Shear, P. K., McElroy, S. L., et al. (2009). Characterizing impulsivity in mania. Bipolar Disorders, 11, 41-51.

Stringaris, A., Santosh, P., Leibenluft, E., \& Goodman, R. (2009). Youth meeting symptom and impairment criteria for mania-like episodes lasting less than four days: an epidemiological study. Journal of Child Psychology and Psychiatry, 51(1), 31-38.

Stroop, J. R. (1935). Studies of interference in serial verbal reactions. Journal of Experimental Psychology, 18, 643-662.

Tannock, R. (1998). Attention-deficit hyperactivity disorder: advances in cognitive, neurobiological, and genetic research. Journal of Child Psychology and Psychiatry, 39, 65-99.

Tham, A., Engelbrektson, K., Mathé, A. A., Johnson, L., Olsson, E., \& Aberg-Wistedt, A. (1997). Impaired neuropsychological performance in euthymic patients with recurring mood disorders. Journal of Clinical Psychiatry, 58, 26-29.

Thompson, J. M., Gallagher, P., Hughes, J. H., Watson, S., Gray, J. M., Ferrier, I. N., et al. (2005). Neurocognitive impairment in euthymic patients with bipolar affective disorder. British Journal of Psychiatry, 186, 32-40.

Toplak, M. E., Rucklidge, J. J., Hetherington, R., John, S. C. F., \& Tannock, R. (2003). Time perception deficits in attention-deficit/ hyperactivity disorder and comorbid reading difficulties in child and adolescent samples. Journal of Child Psychology and Psychiatry, 44, 888-903.

Toplak, M. E., Bucciarelli, S. M., Jain, U., \& Tannock, R. (2009). Executive functions: performance-based measures and the behavior rating inventory of executive function (BRIEF) in adolescents with attention-deficit/hyperactivity disorder (ADHD). Child Neuropsychology, 15, 53-72.

Tripp, G., \& Alsop, B. (1999). Sensitivity to reward frequency in boys with attention deficit hyperactivity disorder. Journal of Clinical Child Psychology, 28, 366-375.

Tripp, G., Ryan, J., \& Peace, K. (2002). Neuropsychological functioning in children with DSM-IV combined type attention deficit hyperactivity disorder. Australian and New Zealand Journal of Psychiatry, 36, 771-779.

Tsal, Y., Shalev, L., \& Mevorach, C. (2005). The diversity of attention deficits in ADHD: the prevalence of four cognitive factors in ADHD versus controls. Journal of Learning Disabilities, 38, $142-157$.

van Leeuwen, T. H., Steinhausen, H. C., Overtoom, C. C., PascualMarqui, R. D., van Klooster, B., Rothenberger, A., et al. (1998). The continuous performance test revisited with neuroelectric mapping: impaired orienting in children with attention deficits. Behavioural Brain Research, 94, 97-110.

van Mourik, R., Oosterlaan, J., \& Sergeant, J. A. (2005). The Stroop revisited: a meta-analysis of interference control in $\mathrm{AD} / \mathrm{HD}$. Journal of Child Psychology and Psychiatry, 46, 150-165.

Voelbel, G. T., Bates, M. E., Buckman, J. F., Pandina, G., \& Hendren, R. L. (2006). Caudate nucleus volume and cognitive performance: are they related in childhood psychopathology? Biological Psychiatry, 60, 942-950.

Wechsler, D. (1991). Wechsler intelligence scale for children (3rd ed.). New York: Psychological Corporation.

Wechsler, D. (1994). Manual for the Wechsler adult intelligence scale (3rd ed.). New York: Psychological Corporation.

Welsh, M. C., Pennington, B. F., \& Groisser, D. B. (1991). A normative-developmental study of executive function: a window on prefrontal function in children? Developmental Neuropsychology, 7, 131-149.

Wiers, R. W., Gunning, W. B., \& Sergeant, J. A. (1998). Is a mild deficit in executive function in boys related to childhood ADHD or parental multigenerational alcoholism? Journal of Abnormal Child Psychology, 26, 415-430.

Wilder-Willis, K. E., Sax, K. W., Rosenberg, H. L., Fleck, D. E., Shear, P. K., \& Strakowski, S. M. (2001). Persistent attentional dysfunction in remitted bipolar disorder. Bipolar Disorders, 3, $58-62$.

Willcutt, E. G., Pennington, B. F., Olson, R. K., Chhabildas, N. A., \& Hulslander, J. (2005). Neuropsychological analyses of comorbidity between reading disability and attention deficit hyperactivity disorder: in search of the common deficit. Developmental Neuropsychology, 27, 35-78.

Wozniak, J., Biederman, J., Kiely, K., Ablon, J. S., Faraone, S. V., Mundy, E., et al. (1995). Mania-like symptoms suggestive of childhood-onset bipolar disorder in clinically referred children. Journal of the American Academy of Child and Adolescent Psychiatry, 34, 867-876.

Wu, K. K., Anderson, V., \& Castiello, U. (2002). Neuropsychological evaluation of deficits in executive functioning for ADHD children with or without learning disabilities. Developmental Neuropsychology, 22, 501-531.

Youngstrom, E. A., Birmaher, B., \& Findling, R. L. (2008). Pediatric bipolar disorder: validity, phenomenology, and recommendations for diagnosis. Bipolar Disorders, 10, 194-214. 